\title{
Creep-Fatigue of Advanced Austenitic Alloys
}

Laura Carroll Julian Benz Richard Wright

August 2010

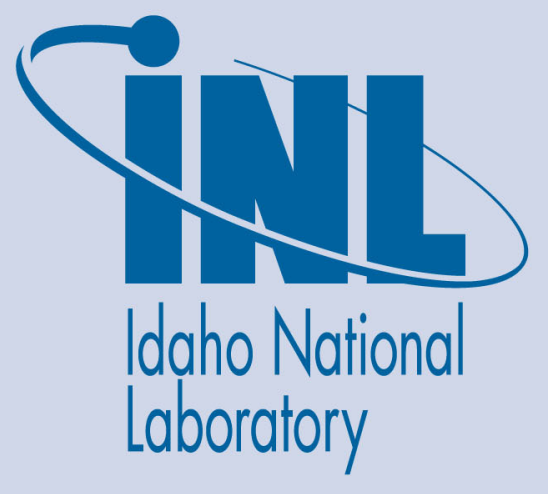

The INL is a U.S. Department of Energy National Laboratory operated by Battelle Energy Alliance 


\section{DISCLAIMER}

This information was prepared as an account of work sponsored by an agency of the U.S. Government. Neither the U.S. Government nor any agency thereof, nor any of their employees, makes any warranty, expressed or implied, or assumes any legal liability or responsibility for the accuracy, completeness, or usefulness, of any information, apparatus, product, or process disclosed, or represents that its use would not infringe privately owned rights. References herein to any specific commercial product, process, or service by trade name, trade mark, manufacturer, or otherwise, does not necessarily constitute or imply its endorsement, recommendation, or favoring by the U.S. Government or any agency thereof. The views and opinions of authors expressed herein do not necessarily state or reflect those of the U.S. Government or any agency thereof. 


\title{
Creep-Fatigue of Advanced Austenitic Alloys
}

\author{
Laura Carroll \\ Julian Benz \\ Richard Wright
}

August 2010

Idaho National Laboratory Idaho Falls, Idaho 83415

http://www.inl.gov

\author{
Prepared for the \\ U.S. Department of Energy \\ Office of Nuclear Energy \\ Under DOE Idaho Operations Office \\ Contract DE-AC07-05ID14517
}





\section{ACKNOWLEDGEMENT}

The authors would like to acknowledge Joel Simpson for conducting the creep-fatigue testing and Todd Morris and Tammy Trowbridge for the metallurgical sample preparation and Scanning Electron Microscopy work. 


\section{CONTENTS}

ACKNOWLEDGEMENT iii

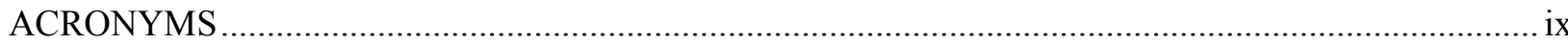

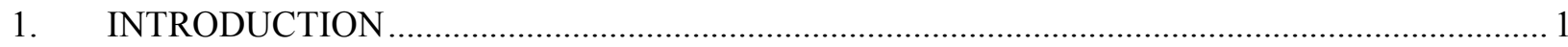

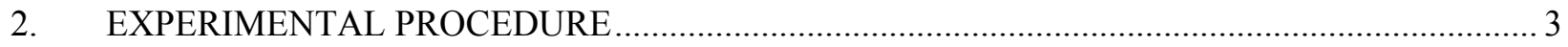

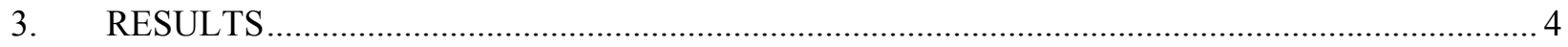

3.1 Characterization of Base Material.............................................................................. 4

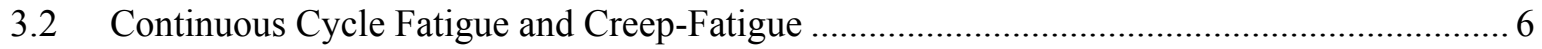

3.3 Metallurgical Analysis of Post-Test Fatigue and Creep-Fatigue Specimens ........................ 10

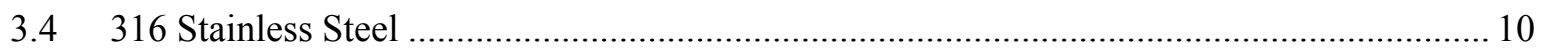

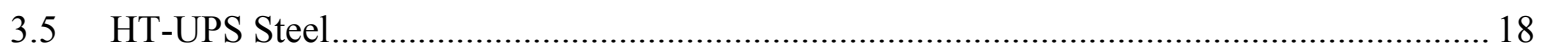

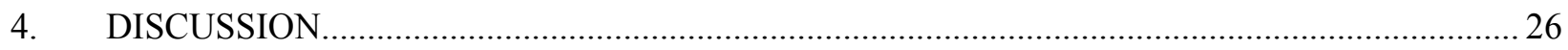

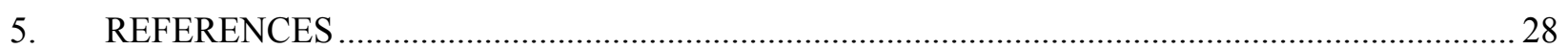

\section{FIGURES}

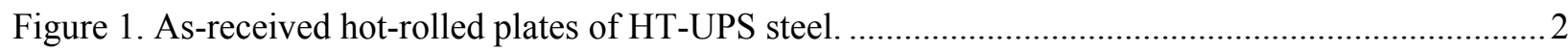

Figure 2. Optical micrograph of HT-UPS base material (a) and the 316 stainless steel base material $(b, c)$. The rolling direction is perpendicular to the plane of the page (a) and the longitudinal axis of the rod is perpendicular to the plane of the page $(b, c)$........................ 4

Figure 3. Three-dimension reconstruction of HT-UPS base material. The reference directions are shown as short transverse, long transverse, and rolling direction........................................... 4

Figure 4. SEM images of the HT-UPS steel after electrolytically etching with an oxalic etch. The etch resulted in pitting in the material that was visible in the SEM. The cuboidal precipitate marked with the number " 2 " in (a) is a Ti-rich precipitate, likely a $\mathrm{Ti}(\mathrm{C}, \mathrm{N})$.

Figure 5. TEM micrograph of HT-UPS in the as-received condition showing the dislocation microstructure and the presence of a few secondary particles within a grain.

Figure 6. Transmission Electron Micrographs of grain boundaries and associated dislocation structures in the as-received stainless steel.

Figure 7. Continuous cycle and creep-fatigue behavior of 316 stainless steel and HT-UPS steel at $600^{\circ} \mathrm{C}$ and $650^{\circ} \mathrm{C}$.

Figure 8. Peak tensile and compressive stresses during continuous cycle fatigue and creep-fatigue deformation of 316 stainless steel and HT-UPS steel at $600^{\circ} \mathrm{C}$.

Figure 9. Peak tensile and compressive stresses during continuous cycle fatigue and creep-fatigue deformation of 316 stainless steel and HT-UPS steel at $650^{\circ} \mathrm{C}$.

Figure 10. Hysteresis loops from low cycle fatigue deformation of 316 stainless steel (a) and HTUPS (b) at $650^{\circ} \mathrm{C}$. Hysteresis loops from creep-fatigue deformation of 316 stainless steel (c) and HT-UPS (d) steel at $650^{\circ} \mathrm{C}$. 
Figure 11. Relaxed stress, the stress at the completion of a hold period, shown along with the peak tensile stress, the stress at the start of a hold period, as a function of cycle for creep-fatigue of 316 stainless steel and HT-UPS steel at $650^{\circ} \mathrm{C}$.

Figure 12. A 316 stainless steel fatigue specimen after testing at $600^{\circ} \mathrm{C}$ and a $1 \%$ total strain. A large crack as well as multiple finer cracks and discoloration due to environmental damage are visible on the specimen surface (a) and (b). Longitudinal imaging reveals that the fine cracks are several grain diameters in depth and typical start transgranularly and propagate in a transgranular manner (c) and (d). The large macrocrack is shown in (e).

Figure 13. A 316 stainless steel creep-fatigue specimen after testing at $600^{\circ} \mathrm{C}, 1 \%$ total strain, and a 10 minute hold time at peak tensile strain. A large crack as well as multiple finer cracks and discoloration due to environmental damage are visible on the specimen surface (a) and (b). Longitudinal images reveal that the fine cracks are many grain diameters in depth and typical start intergranularly and propagate in a transgranular manner (c) and (d) and (e).

Figure 14. A 316 stainless steel fatigue specimen after testing at $650^{\circ} \mathrm{C}$ and a $1 \%$ total strain. Longitudinal images reveal that the fine cracks are several grain diameters in depth and typical start intergranularly and propagate in a predominately transgranular manner (a) and (b), despite the presence of small branches at intersecting grain boundaries. There is a significant amount of oxidation visible in the crack (c).

Figure 15 . Oxide in the crack of a 316 stainless steel fatigue specimen after testing at $650^{\circ} \mathrm{C}$ and a $1 \%$ total strain. The number " 1 " and " 2 " in (a) correspond to the EDS spectra in (b) and (c), respectively......

Figure 16. A 316 stainless steel creep-fatigue specimen after testing at $650^{\circ} \mathrm{C}, 1 \%$ total strain, and a 10 minute hold. Longitudinal images reveal that the fine cracks extend several grain diameters in depth from the specimen surface and typical start intergranularly and propagate in a predominately transgranular manner (a) and (b), despite the presence of small branches at intersecting grain boundaries. There is a significant amount of oxide visible in the crack (c).

Figure 17. The surface of a 316 stainless steel creep-fatigue specimen after testing at $650^{\circ} \mathrm{C}, 1 \%$ total strain, and a 10 minute hold (a), (b), and (c). A SEM image illustrating the cracking and its relationship to the surface oxide (a). Higher magnification images of the surface oxide remaining on the specimen surface after mounting, polishing, and etching (b) and (c). The EDS spectra for the outer oxide 1 (d), 2 (e), and 3 (f) as labeled in (b).

Figure 18. TEM bright field micrographs of 316 stainless steel after creep-fatigue testing showing the dislocation arrangements and cellular pattern (a) and the fine equiaxed substructure (b) which emerges.

Figure 19. A 316 creep-fatigue specimen showing grain boundary carbides, likely $\mathrm{M}_{23} \mathrm{C}_{6}$, and dislocation tangles within the grains....

Figure 20. Optical micrographs of a HT-UPS specimen after fatigue deformation at $600^{\circ} \mathrm{C}$ and $1 \%$ total strain.

Figure 21. Optical micrographs of a HT-UPS specimen after creep-fatigue deformation at $600^{\circ} \mathrm{C}$, 10 minute hold, and a 1\% total strain. Cracks are observed to initiate both intergranularly (a) and transgranularly (b). Crack paths are independent of grain boundaries, propagating in a transgranular manner. 
Figure 22. Optical micrographs of a HT-UPS specimen after fatigue deformation at $650^{\circ} \mathrm{C}$ and a $1 \%$ total strain. Cracks are observed to initiate and propagate transgranularly.

Figure 23. SEM micrographs of a HT-UPS specimen after fatigue deformation at $650^{\circ} \mathrm{C}$ and a $1 \%$ total strain. The surface oxide is shown in (a) and an oxide-filled tip of a secondary crack is shown in (b).

Figure 24. Optical micrographs of a HT-UPS specimen after fatigue deformation at $650^{\circ} \mathrm{C}, 10$ min hold, and a $1 \%$ total strain. Cracks are observed to initiate intergranularly and propagate in a transgranular manner.....

Figure 25. SEM micrographs of a HT-UPS specimen after fatigue deformation at $650^{\circ} \mathrm{C}, 10 \mathrm{~min}$ hold, and a $1 \%$ total strain. An oxide that has formed on the specimen surface is shown in (a) and oxide-filled cracks are shown in (b) and (c). Fine precipitates are present on the grain boundaries (d).

Figure 26. TEM micrographs of second phase particles, likely $\mathrm{M}_{23} \mathrm{C}_{6}$ carbides, which have precipitated on grain boundaries in the post creep-fatigue HT-UPS material.

Figure 27. TEM micrograph of HT-UPS stainless steel showing nanometer sized MC carbides within the grains after creep-fatigue testing.

Figure 28. Dislocations pinned within the grains by the large percentage of MC carbides in HTUPS material

\section{TABLES}

Table 1. Composition of the austenitic steels, 316 stainless and HT-UPS steel, in wt\%. 3

Table 2. Continuous cycle and creep-fatigue behavior of 316 stainless steel and HT-UPS steel at $600^{\circ} \mathrm{C}$ and $650^{\circ} \mathrm{C}$. In the cases for which failure lives were not available at the $20 \%$ drop in peak stress criteria $\left(\mathrm{N}_{20}\right)$, a $10 \%$ drop $\left(\mathrm{N}_{10}\right)$ was alternatively used. 


\section{ACRONYMS}




\section{Creep-Fatigue of Advanced Austenitic Alloys}

\section{INTRODUCTION}

The development of new structural materials for fast reactors and energy-conversion systems is of interest for increased operating temperatures and longer component lifetimes. Currently, the heat resistant components use primarily conventional austenitic stainless steels in the temperature regime of 600 to $650^{\circ} \mathrm{C}$. ${ }^{1}$ The goal of new structural materials is to develop an advanced austenitic alloy that offers improved strength and/or oxidation resistance, ${ }^{1}$ particularly at temperatures in excess of $600^{\circ} \mathrm{C}$. The higher strengths and/or improved oxidation resistance of these materials allows for longer component lifetimes. Additionally, these advanced austenitic alloys are designed to have lower costs than nickel-base alloys to which they may offer comparable high temperature properties.

A series of high strength austenitic alloys have been developed and are referred to as HT-UPS (high temperature ultrafine-precipitation strengthened) steels. ${ }^{1,2,3}$ These alloys are based on a strengthening concept similar to that of nano-scale precipitation strengthened martensitic steels; strengthened by controlling the dispersion of MC carbides and carbonitrides through additions of $\mathrm{Nb}$ and $\mathrm{V} .{ }^{4} \mathrm{HT}$-UPS steel development has also attempted to strength an austenitic alloy through $\mathrm{Ti}, \mathrm{V}, \mathrm{Nb}$ carbonitrides $(\mathrm{M}(\mathrm{C}, \mathrm{N}))$ while improving the oxidation resistance by the addition of sufficient Al to result in an alloy that forms a continuous Al-rich oxide, opposed to the traditional $\mathrm{Fe}-\mathrm{Cr}$-rich oxide, at high temperature. ${ }^{5}$ The creep-fatigue work reported herein has been conducted on a base HT-UPS alloy, which does not contain Al, and a conventional austenitic stainless steel alloy, type 316. The creep strength of the HT-UPS steel is comparable to Alloy 617, the temperatures of interest to the structural components of fast reactors are lower than would necessitate the use of a nickel-base alloy. Comparison of the fatigue and creepfatigue properties of HT-UPS steel was conducted at $600^{\circ} \mathrm{C}$ and $650^{\circ} \mathrm{C}$ in line with the use temperature of structural components in fast reactors.

Creep-fatigue damage is an important in-service degradation mode of structural materials. The characterization of the creep-fatigue properties of newly developed structural materials is important to assess their resistance to cyclical loading and thermal fluctuations occurring in the structural components of reactors. Creep-fatigue cycling replicates thermally-induced cyclic loading that is interrupted by a period of high temperature operation during which creep deformation occurs. Laboratory creep-fatigue testing is typically conducted in a strain-controlled manner to most closely replicate fluctuating thermal strains in the material. The stresses relax during the hold period at maximum tensile strain. It is during this hold that elastic strain is transferred to plastic strain thus plastic deformation occurs. The hold period introduces both a creep and environmental component to fatigue deformation. 


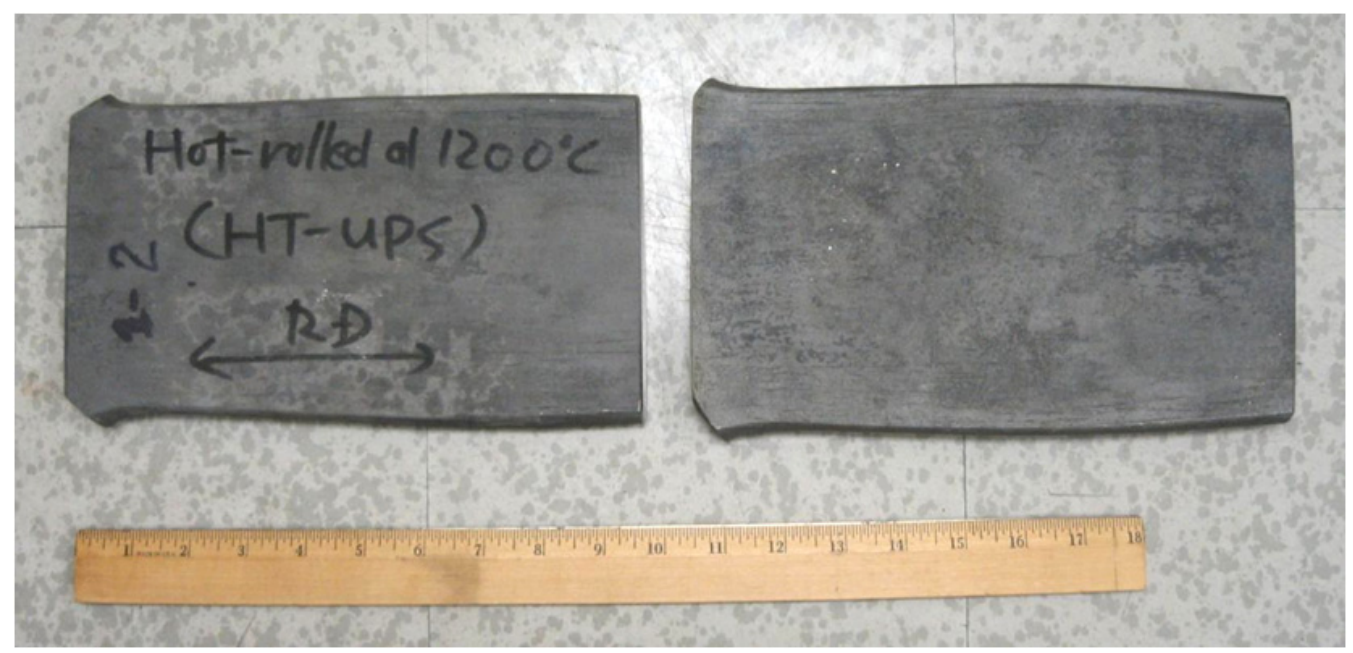

Figure 1. As-received hot-rolled plates of HT-UPS steel.

The 316 stainless steel alloy is commonly used for structural components of nuclear reactors and therefore was selected for a baseline comparison of the HT-UPS fatigue and creep-fatigue properties. As mentioned previously, the HT-UPS alloy is strengthen by nano-scale MC ( $\mathrm{NbC}, \mathrm{TiC}$, or VC) precipitates and is much more creep resistant than the conventional stainless steels. The comparison of the two alloys that have different creep resistances may show different responses to creep-fatigue deformation. Typically, the HT-UPS alloys require prior cold work to form sufficient dislocations to serve as nucleation sites for the precipitation of the nano-scale precipitates. The creep-fatigue work reported herein was conducted in the annealed, hot forged, and hot rolled state, however, dislocations are introduced into the material during the initial creep-fatigue cycles. 


\section{EXPERIMENTAL PROCEDURE}

An ingot of HT-UPS steel was cast into the dimensions 4" in diameter and 5" in length, as shown in Figure 1. The ingot was annealed at $1200^{\circ} \mathrm{C}$ for 4 hours in an argon and $4 \% \mathrm{H}_{2}$ gas atmosphere. The plate was hot forged at $1200^{\circ} \mathrm{C}$ to a thickness of approximately 2 " and then hot rolled at $1200^{\circ} \mathrm{C}$ to a thickness of 0.8 ". The plates were air cooled following the hot forging and hot rolling steps. After reducing the plates to a final thickness of 0.8 ", the plates were sandblasted to remove the oxide scales and the edges were removed. The chemistry of the HT-UPS steel plate is given in Table 1. Bar stock of 316 stainless steel was purchased in the form of 0.75 inch round bar in the annealed, pickled, and cold drawn state. The composition for this heat of 316 stainless steel is also included in Table 1.

Table 1. Composition of the austenitic steels, 316 stainless and HT-UPS steel, in wt $\%$.

\begin{tabular}{|l|c|c|c|c|c|c|c|c|c|c|c|c|c|}
\hline & $\mathrm{Fe}$ & $\mathrm{Cr}$ & $\mathrm{Mo}$ & $\mathrm{Nb}$ & $\mathrm{Ni}$ & $\mathrm{Mn}$ & $\mathrm{Ti}$ & $\mathrm{Si}$ & $\mathrm{Al}$ & $\mathrm{V}$ & $\mathrm{B}$ & $\mathrm{C}$ & $\mathrm{S}$ \\
\hline 316 & $\mathrm{bal}$ & 17.1 & 2.1 & & 10.7 & 1.6 & 0.005 & 0.37 & 0.13 & & & 0.02 & 0.02 \\
\hline HT-UPS & 63.6 & 14.5 & 2.3 & 0.15 & 16.1 & 2.1 & 0.15 & 0.28 & 0.26 & 0.53 & 0.007 & 0.06 & $6^{*}$ \\
\hline *ppm & \multicolumn{10}{|l|}{} \\
\hline
\end{tabular}

Creep-fatigue specimens were machined from the hot rolled HT-UPS plate and the as-received 316 rod in to a creep-fatigue specimen corresponding to INL (Idaho National Laboratory) drawing number 760368. The creep-fatigue specimen has a straight-sided collet-grip type end and was designed in accordance with ASTM Standard E606-04 for strain-controlled fatigue testing. The final machining steps were performed with low stress grinding to avoid introducing residual stresses in the specimens. Continuous cycle fatigue and creep-fatigue testing was conducted in a strain-controlled manner in servohydraulic test frames. The continuous cycle fatigue tests had a fully reversed, triangular waveform with a strain rate of $10^{-3} / \mathrm{sec}$. The creep-fatigue tests were conducted with a similar wave shape, however, a hold time was introduced at peak tensile strain. Hold times as short as 1 minute and as long as 60 minutes were investigated.

After creep-fatigue testing, the gage section of selected specimens was cut in half parallel to the stress (specimen) axis. The longitudinal cut was made through the largest crack and the cut face was then mounted and polished. A final polishing step of colloidal alumina was used to avoid reaction with the $\mathrm{Cl}^{-}$ ions in the etch. The specimens were then etched with several different reagents, based on the intended use of the mounts, including Vilella's reagent $(20 \mathrm{ml}$ ethanol, $1 \mathrm{~g}$ picric acid, and $1 \mathrm{ml} \mathrm{HCl})$, oxalic acid, and 3:3:1 $\mathrm{H}_{2} \mathrm{O}, \mathrm{HCl}, \mathrm{HNO}_{3}$. Base material from one of the-HT-UPS plates from each of the three orientations and base material perpendicular to the rod axis of 316 stainless steel was also mounted, polished, and etched.

Additionally, transmission electron microscopy (TEM) specimen were prepared by first mechanical cutting thin slices parallel to the stress axis with a low speed saw from bulk material or the gage section of deformed creep-fatigue specimens. The slices were then mechanical ground to approximately $125 \mu \mathrm{m}$. A punch was used to obtain $3 \mathrm{~mm}$ diameter discs from the thinned material. The discs were then electropolished using a twin jet TenuPol polisher with a $10 \%$ perchloric acid in ethanol solution at approximately $0^{\circ} \mathrm{C}$. A JOEL JEM-2010 HR Analytical Transmission Electron Microscope was used at $200 \mathrm{kV}$ for microstructural characterization. 


\section{RESULTS}

\subsection{Characterization of Base Material}

The microstructure of the as-received HT-UPS plate was relatively homogenous. An optical image perpendicular to the rolling direction is shown in Figure 2(a). All three orientations of one of the plates were examined and the microstructure and grain size were consistent, as shown in a three-dimensional reconstruction of the microstructure in Figure 3. The grain size was approximately $100 \mu \mathrm{m}$ and twins were observed throughout the grain structure. Also visible optically were $\operatorname{Ti}(\mathrm{C}, \mathrm{N})$ precipitates that were typically cuboidal in shape and on the order of a micron on edge.

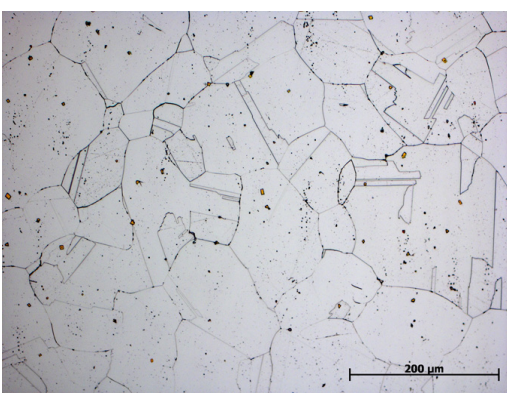

(a)

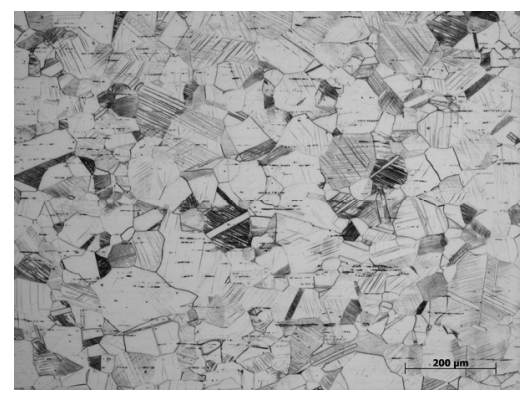

(b)

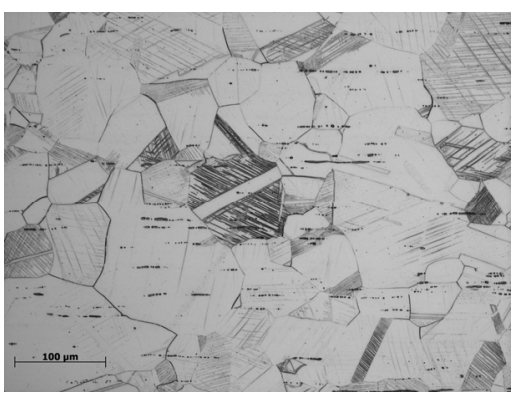

(c)

Figure 2. Optical micrograph of HT-UPS base material (a) and the 316 stainless steel base material (b, c). The rolling direction is perpendicular to the plane of the page (a) and the longitudinal axis of the rod is perpendicular to the plane of the page $(b, c)$.
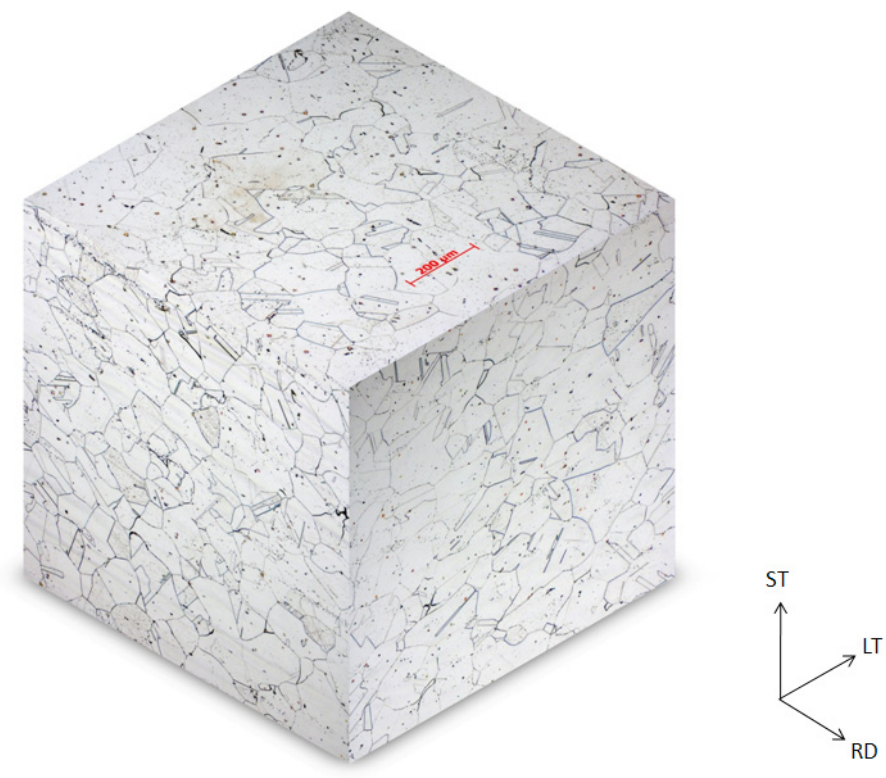

Figure 3. Three-dimension reconstruction of HT-UPS base material. The reference directions are shown as short transverse, long transverse, and rolling direction. 
The base HT-UPS material was difficult etch without causing extensive grain boundary and intragranular pitting and thus imaging the alloy with the SEM was challenging. The commonly used stainless steel etchants that were used resulted in pitting that was visible in the SEM. An SEM image showing pitting is shown for HT-UPS etched with an oxalic etch in Figure 4. The pitting was not observed in the as-polished base material. A light etch with Vilella's reagent was found to not result in pitting, however, the light etch did not sufficiently reveal the grain structure for optical microscopy. SEM work was performed on lightly etched specimen and optical microscopy was completed on specimen etched for longer times.

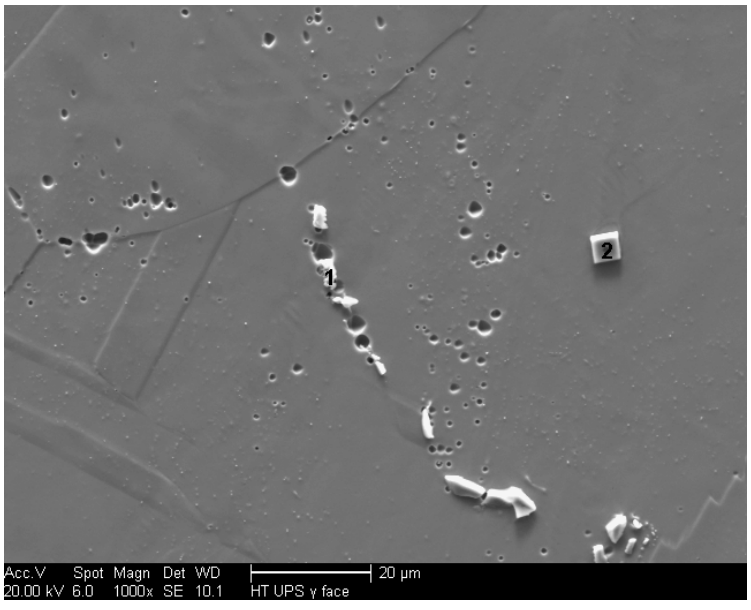

(a)

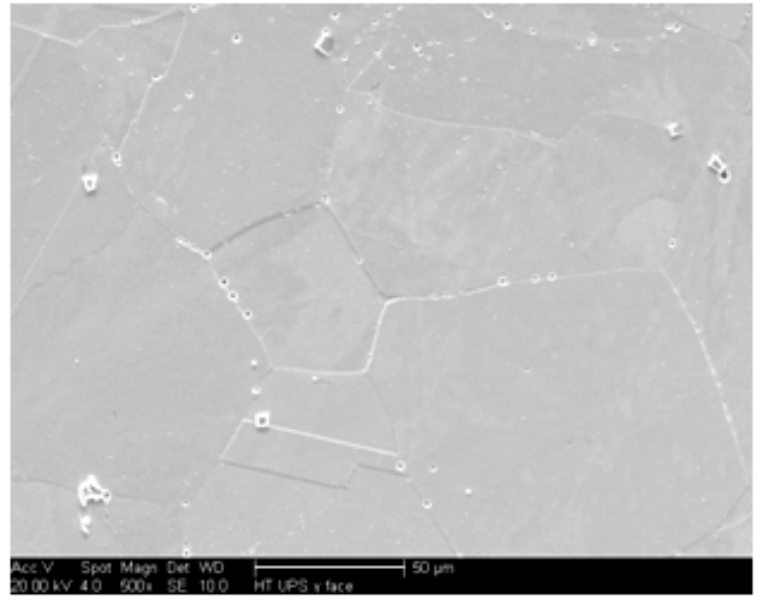

(b)

Figure 4. SEM images of the HT-UPS steel after electrolytically etching with an oxalic etch. The etch resulted in pitting in the material that was visible in the SEM. The cuboidal precipitate marked with the number " 2 " in (a) is a Ti-rich precipitate, likely a Ti(C,N).

Transmission electron microscopy (TEM) of the as-received HT-UPS material was completed to characterize secondary phases and obtain a baseline microstructure for later analysis of creep-fatigue samples. Figure 5 shows a bright-field TEM image of the as-received material showing dislocations within one grain. As expected, the dislocation density is very low due to the final hot rolling of the material. Also, very few secondary particles are present. A small number of particles which are approximately $50 \mathrm{~nm}$ in diameter, most likely $\mathrm{MC}$ carbides, were found adjacent to intragranular dislocations as indicated by the arrows in Figure 5.

The microstructure of 316 stainless steel base material is shown in Figure 2(b) and (c). Slip lines are present in many of the grains, evidence of the cold working prior to receipt of the material. The prior deformation is also visible parallel to the rolling directions in wavy lines (image not shown). The grain size of the stainless steel was not quantified, though the grains are smaller than the HT-UPS material. TEM micrographs of the as- received materials are shown in Figure 6 and reveal a small fraction of secondary phases within the grains. Images of the grain boundaries were also acquired. A low grain boundary and the associated dislocation network are shown in Figure 6; the boundary is void of second phase particles. 


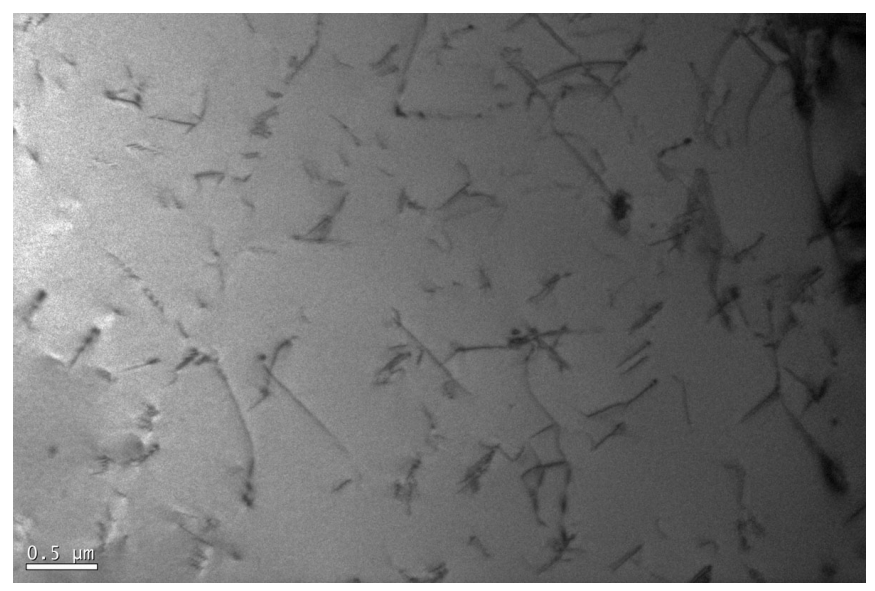

Figure 5. TEM micrograph of HT-UPS in the as-received condition showing the dislocation microstructure and the presence of a few secondary particles within a grain.

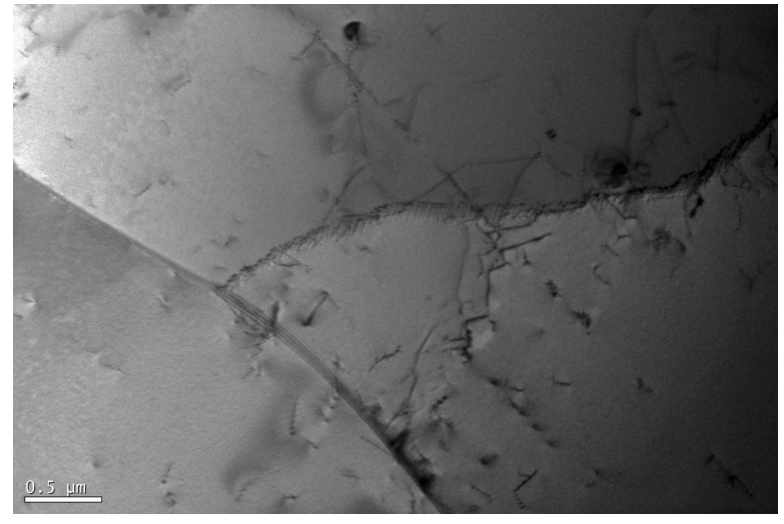

(a)

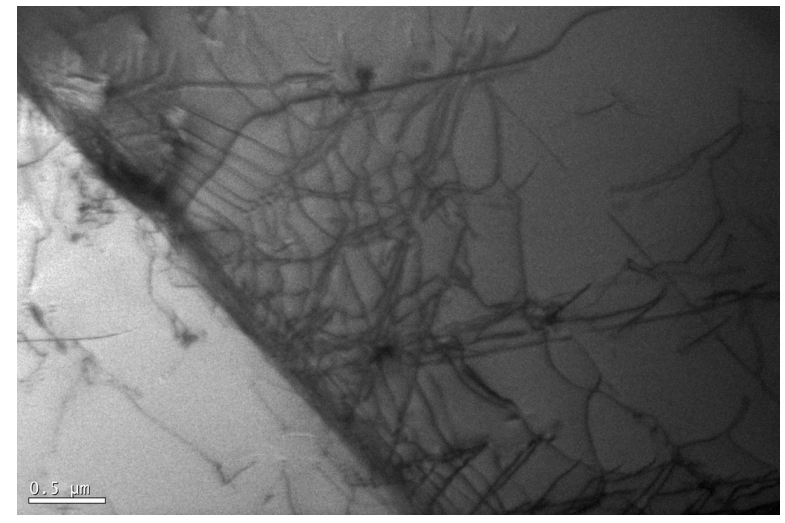

(b)

Figure 6. TEM micrographs of grain boundaries and associated dislocation structures in the as-received 316 stainless steel.

\subsection{Continuous Cycle Fatigue and Creep-Fatigue}

The fatigue and creep-fatigue lives of the HT-UPS and the 316 stainless steel alloy were similar, although the deformation behavior during cycling was quite different. A summary of the fatigue and creep-fatigue results are given in Table 2. As illustrated in Figure 7, the number of cycles to failure of the 316 stainless steel and the HT-UPS steel were similar at $600^{\circ} \mathrm{C}$ and $650{ }^{\circ} \mathrm{C}$. The cycles to failure at the higher temperature, $650^{\circ} \mathrm{C}$, were slightly less than at $600^{\circ} \mathrm{C}$. At these conditions, increasing hold times of up to 10 minutes did not degrade the creep-fatigue life of either alloy. For the 316 stainless steel, longer hold times of 30 and 60 minutes at $650^{\circ} \mathrm{C}$ resulted in cycle lifetimes that were slightly lower than observed for the shorter hold times. The HT-UPS creep-fatigue specimen tested with a 30 minute hold time at peak tensile strain failed in a similar number of cycles as the continuous cycle and shorter hold time tests. A 60 minute hold time HT-UPS creep-fatigue test is currently in progress. Creep-fatigue tests with hold times in excess of 10 minutes were not conducted at the $600^{\circ} \mathrm{C}$ temperature. 
Table 2. Continuous cycle and creep-fatigue behavior of 316 stainless steel and HT-UPS steel at $600^{\circ} \mathrm{C}$ and $650^{\circ} \mathrm{C}$. In the cases for which failure lives were not available at the $20 \%$ drop in peak stress criteria $\left(\mathrm{N}_{20}\right)$, a $10 \%$ drop $\left(\mathrm{N}_{10}\right)$ was alternatively used.

\begin{tabular}{|c|c|c|c|c|c|c|c|c|c|c|c|c|c|}
\hline Alloy & Specimen ID & Temp & $\begin{array}{l}\text { Total } \\
\text { Strain } \\
\text { Range } \\
\end{array}$ & $\begin{array}{c}\text { Inelastic } \\
\text { Strain } \\
\text { Range } \\
@ \\
\text { Midlife } \\
\end{array}$ & $\begin{array}{c}\text { Tensile } \\
\text { Hold } \\
\text { Time }\end{array}$ & $\begin{array}{c}\text { Stable } \\
\text { Load } \\
\text { Range }\end{array}$ & $\begin{array}{c}\text { Stable } \\
\text { Stress } \\
\text { Max }\end{array}$ & $\begin{array}{c}\text { Stable } \\
\text { Stress } \\
\text { Min }\end{array}$ & $\begin{array}{c}\text { Cycles } \\
\text { for } \\
\text { Stable } \\
\end{array}$ & $\begin{array}{c}\text { Cycles } \\
\text { to } \\
\text { Initiation }\end{array}$ & \begin{tabular}{|c|} 
Cycles \\
to Failure
\end{tabular} & $\begin{array}{c}\text { Cycles } \\
\text { to Failure }\end{array}$ & $\begin{array}{l}\text { Time to } \\
\text { Failure }\end{array}$ \\
\hline & & $\left({ }^{\circ} \mathrm{C}\right)$ & $(\%)$ & $(\%)$ & $(\min )$ & $(\mathrm{kN})$ & (MPa) & $(\mathrm{MPa})$ & Stress & $\left(\mathrm{N}_{0}\right)$ & $\left(N_{10}\right)$ & $\left(\mathrm{N}_{20}\right)$ & (hrs) \\
\hline 316 & 316-STD-01 & 600 & 1.0 & 0.62 & 0 & $13.5 /-13.5$ & 300 & -300 & 150 & 1151 & & 1244 & 6.9 \\
\hline 316 & 316-STD-04 & 600 & 1.0 & 0.63 & 0 & $13.6 /-13.8$ & 302 & -306 & 200 & 1475 & & 1551 & 8.6 \\
\hline 316 & 316-STD-06 & 600 & 1.0 & 0.62 & 0 & 12.6/-13.1 & 285 & -298 & 275 & 1366 & & 1716 & 9.5 \\
\hline HT-UPS & U-9 & 600 & 1.0 & 0.495 & 0 & $14.7 /-15.3$ & 333 & -348 & 150 & 900 & 1627 & 1705 & 9.5 \\
\hline 316 & 316-STD-02 & 600 & 1.0 & 0.64 & 1 & $13.1 /-13.2$ & 289 & -296 & 150 & 1262 & & 1425 & 31.7 \\
\hline 316 & 316-STD-05 & 600 & 1.0 & 0.65 & 5 & 12.9/-13.3 & 289 & -293 & 250 & 1489 & & 1744 & 155.0 \\
\hline 316 & 316-STD-07 & 600 & 1.0 & 0.68 & 5 & 11.9/-12.3 & 266 & -280 & 150 & 828 & & 1384 & 123.0 \\
\hline 316 & 316-STD-03 & 600 & 1.0 & 0.68 & 10 & $12.5 /-12.8$ & 280 & -288 & 150 & 1312 & & 1437 & 247.5 \\
\hline HT-UPS & U-8 & 600 & 1.0 & 0.548 & 10 & $15.1 /-17.1$ & 356 & -384 & 150 & 1055 & 1605 & 1755 & 302.3 \\
\hline 316 & 316-STD-10 & 650 & 1.0 & 0.67 & 0 & $10.9 /-11.4$ & 238 & -246 & 150 & 947 & & 1093 & 6.1 \\
\hline HT-UPS & $\mathrm{U}-4$ & 650 & 1.0 & 0.545 & 0 & $14.6 /-15.4$ & 333 & -353 & 375 & 586 & 1018 & & 5.7 \\
\hline 316 & 316-STD-13 & 650 & 1.0 & 0.72 & 5 & $10.5 /-11.5$ & 227 & -240 & 150 & 283 & & 1110 & 98.7 \\
\hline 316 & 316-STD-12 & 650 & 1.0 & 0.690 & 10 & $11.3 /-11.4$ & 247 & -247 & 150 & 1061 & & 1260 & 217.0 \\
\hline HT-UPS & U-5 & 650 & 1.0 & 0.621 & 10 & $14.3 /-15.8$ & 322 & -360 & 200 & 439 & & 1127 & 194.0 \\
\hline 316 & 316-STD-11 & 650 & 1.0 & 0.72 & 30 & $10.8 /-11.3$ & 235 & -247 & 75 & 783 & & 972 & 491.4 \\
\hline HT-UPS & U-10 & 650 & 1.0 & 0.649 & 30 & $13.5 / 14.75$ & 309 & -335 & 150 & 1174 & 1287 & 1365 & 690.1 \\
\hline 316 & 316-STD-14 & 650 & 1.0 & 0.73 & 60 & 10.9/11.7 & 238 & -253 & 100 & 683 & & 902 & 907.0 \\
\hline HT-UPS & U-11 & 650 & 1.0 & & 60 & & & & & & & & \\
\hline
\end{tabular}

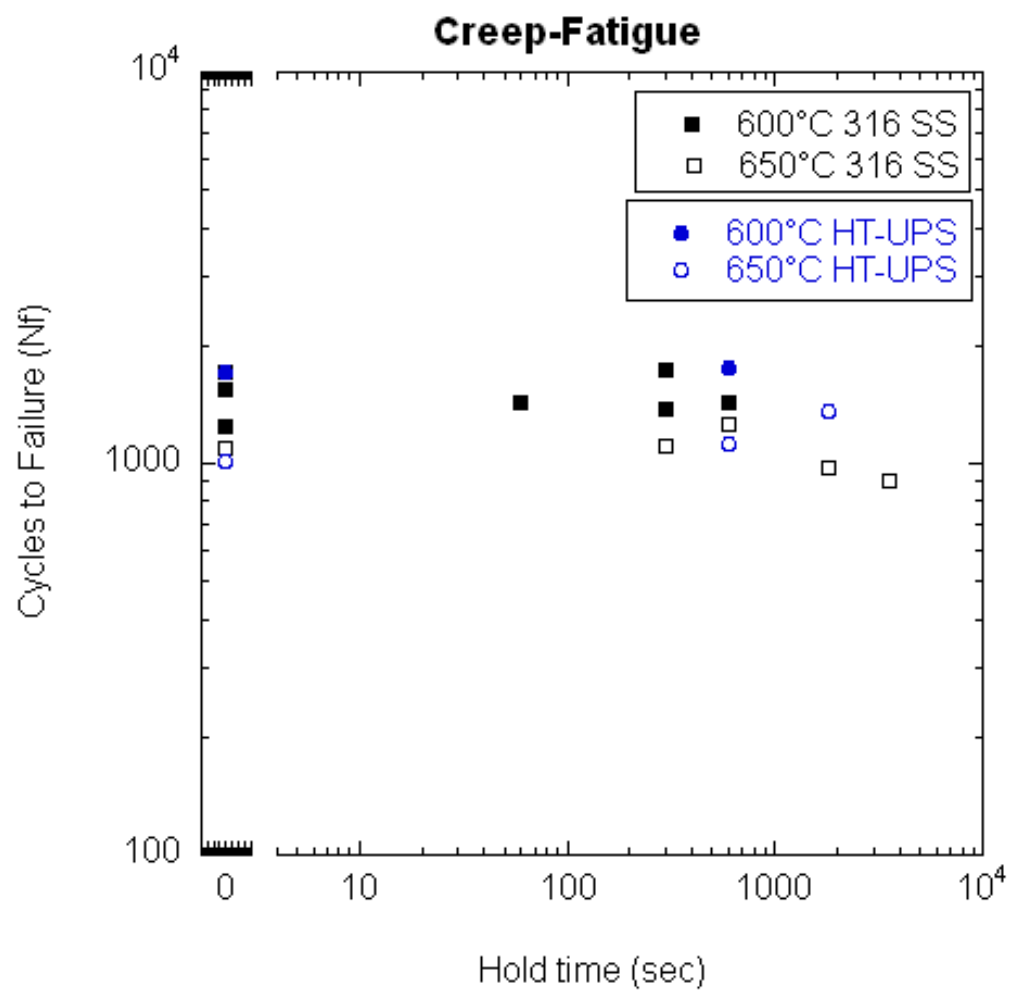

Figure 7. Continuous cycle and creep-fatigue behavior of 316 stainless steel and HT-UPS steel at $600^{\circ} \mathrm{C}$ and $650^{\circ} \mathrm{C}$. 
Although the cycles to failure were similar for the two steels, differences were observed in the cyclic hardening behavior. The peak stresses for the continuous cycle and 10 minute hold creep-fatigue tests are shown as a function of cycle in Figure 8 and Figure 9, at $600^{\circ} \mathrm{C}$ and $650^{\circ} \mathrm{C}$, respectively. In low cycle fatigue at $600^{\circ} \mathrm{C}$, the HT-UPS alloy exhibited relatively low tensile and compressive peak stresses initially and then significant hardening was observed as the peak tensile and compressive stresses more than doubled during the first 250 cycles. The peak tensile stress increased from approximately $130 \mathrm{MPa}$ to greater than $300 \mathrm{MPa}$. The 316 stainless steel had a higher peak stress, approximately $310 \mathrm{MPa}$, in the initial fatigue cycles, then exhibited minimal hardening for the first 50 cycles, followed by softening for a hundred cycles and finally stabilizing at a stress of $300 \mathrm{MPa}$. The peak stresses of 316 and HT-UPS during creep-fatigue deformation at $600^{\circ} \mathrm{C}$ were initially similar to those exhibited during fatigue. However, the HT-UPS alloy continued to cyclically soften throughout the creep-fatigue test, whereas during the fatigue test a stabilized stress was established, also shown in Figure 8. Cyclic softening during deformation was much less pronounced in the 316 stainless steel at $600^{\circ} \mathrm{C}$.

At $650^{\circ} \mathrm{C}$, the cyclic stress response of the HT-UPS steel during fatigue and creep-fatigue deformation was similar to that at $600^{\circ} \mathrm{C}$. However, the 316 material at $650^{\circ} \mathrm{C}$ did not initially harden as was observed at the lower temperature, instead cyclic softening occurred for approximately 50 cycles at which point both the fatigue and creep-fatigue tests achieved a stable peak tensile and compressive stress until macrocrack initiation, as shown in Figure 9.

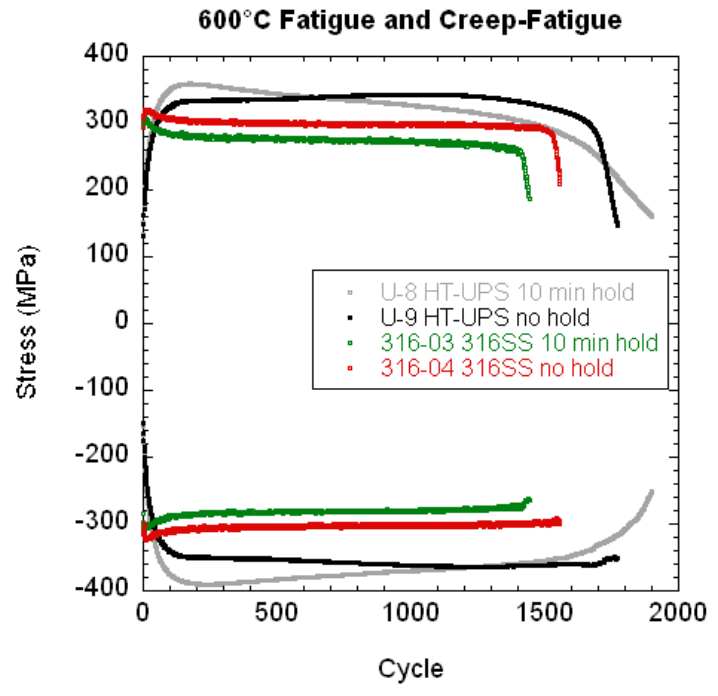

Figure 8. Peak tensile and compressive stresses during continuous cycle fatigue and creep-fatigue deformation of 316 stainless steel and HT-UPS steel at $600^{\circ} \mathrm{C}$.

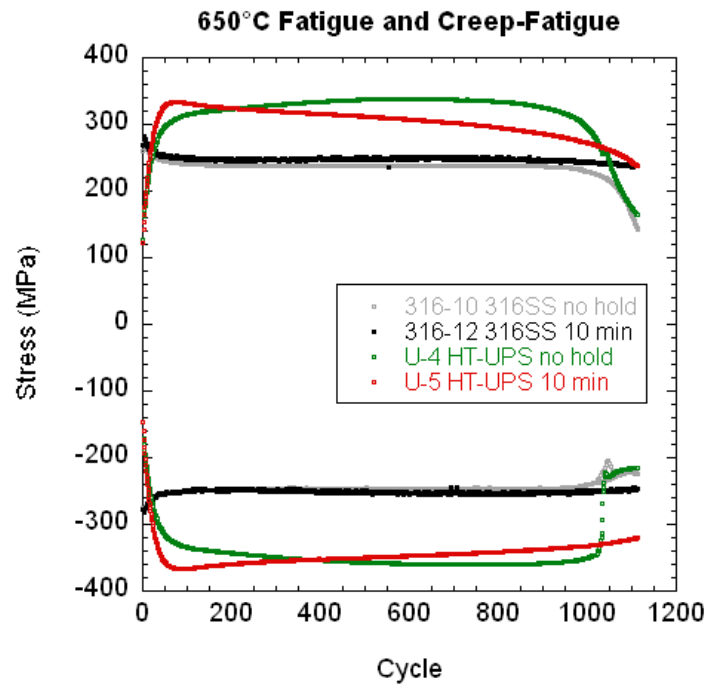

Figure 9. Peak tensile and compressive stresses during continuous cycle fatigue and creep-fatigue deformation of 316 stainless steel and HT-UPS steel at $650^{\circ} \mathrm{C}$.

Hysteresis loops are shown for cycles 1, 10, 100, and a midlife cycle of the fatigue and the 10 minute hold creep-fatigue deformation for 316 stainless steel and HT-UPS steel in Figure 10. Consistent with the peak stress versus cycle, the hysteresis loops for 316 have approximately equivalent peak tensile and compressive stresses as well as inelastic strains, defined here as the width of the hysteresis loop at zero stress. The substantial hardening observed in the HT-UPS steel is evident in the selected hysteresis loops; the width of the loop decreases and the peak stresses increase with increasing cycle. Serrated yielding was observed during the initial cycles of deformation. 


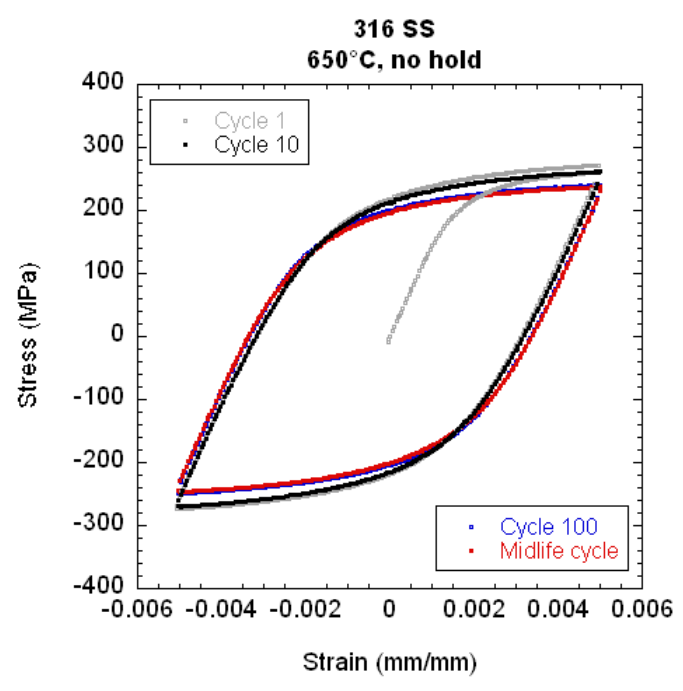

(a)

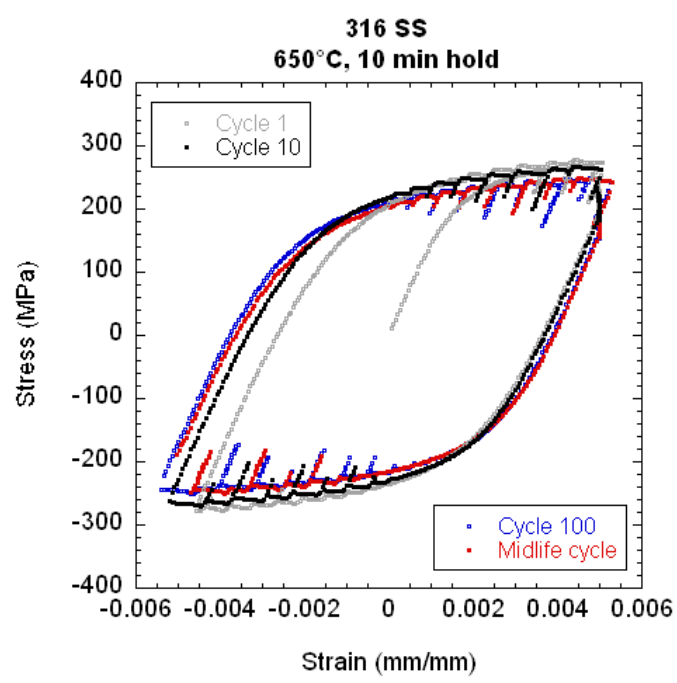

(c)

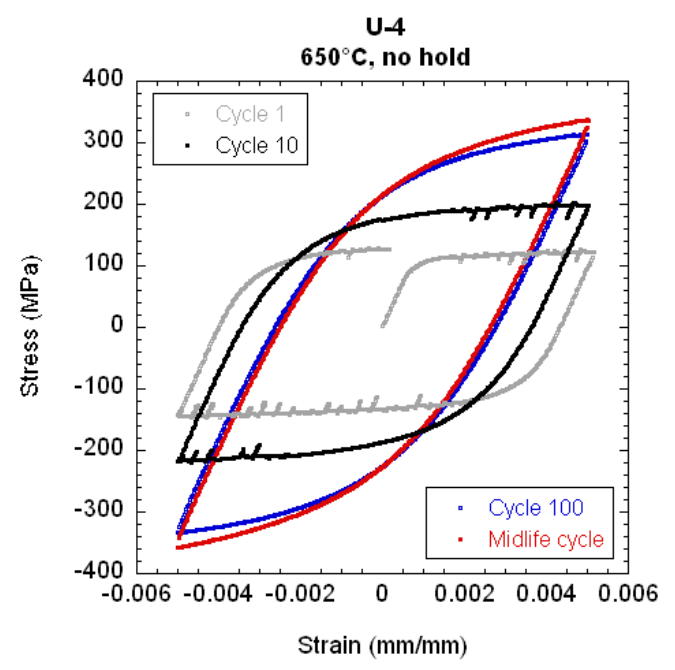

(b)

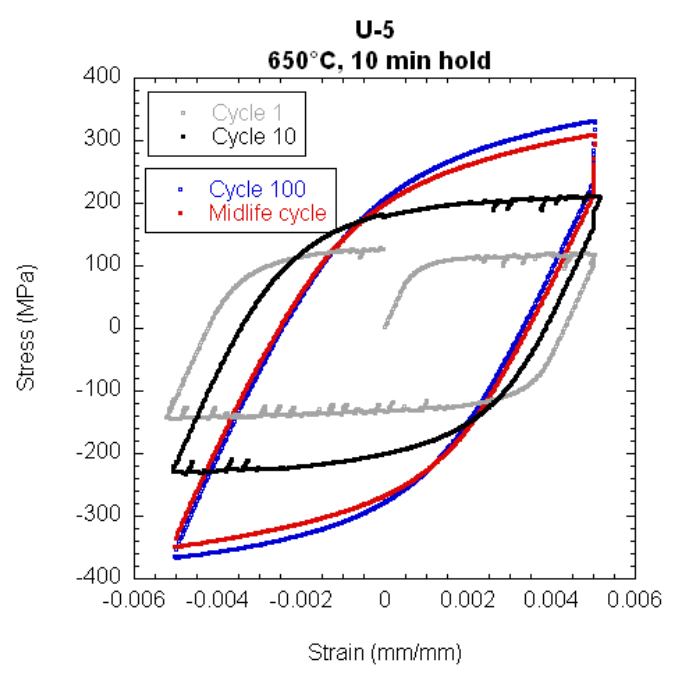

(d)

Figure 10. Hysteresis loops from low cycle fatigue deformation of 316 stainless steel (a) and HT-UPS (b) at $650^{\circ} \mathrm{C}$. Hysteresis loops from creep-fatigue deformation of 316 stainless steel (c) and HT-UPS (d) steel at $650^{\circ} \mathrm{C}$.

It is also informative to compare the creep or tensile hold portion of the cycle for the two alloys, although this is somewhat difficult given the large differences in the peak stresses. It has been well documented that the creep strength of the HT-UPS alloy is significantly higher than conventional stainless steels ${ }^{1}$ on the order of 100 times at $700^{\circ} \mathrm{C} .^{3}$ The relaxed stresses or the stress at the completion of the hold period are shown with the peak tensile stresses for creep-fatigue at $650^{\circ} \mathrm{C}$ and a 10 minute hold in Figure 11. The stress at the end of the hold period for both 316 and HT-UPS vary as a function of the peak stress. For example, the peak stresses of HT-UPS initially increase and then slowly decrease, the relaxed stresses follow a similar trend. The relaxed stresses observed for the 316 stainless steel are significantly lower than the relaxed stresses observed for the HT-UPS alloy. As shown in Figure 10(d) for the HT-UPS alloy, the difference in the peak stress and the relaxed stress is relatively small in the initial cycles and becomes more significant by the $100^{\text {th }}$ cycle. 


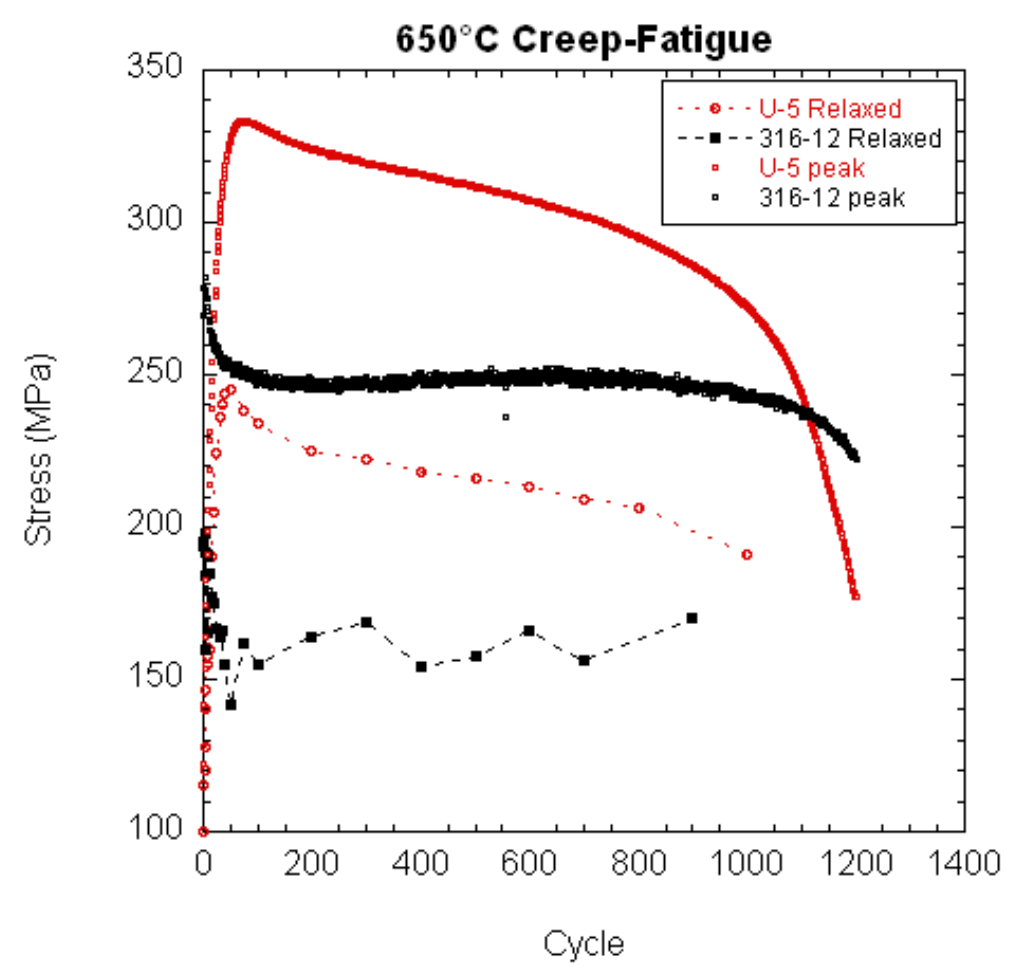

Figure 11. Relaxed stress, the stress at the completion of a hold period, shown along with the peak tensile stress, the stress at the start of a hold period, as a function of cycle for creep-fatigue of 316 stainless steel and HT-UPS steel at $650^{\circ} \mathrm{C}$.

\subsection{Metallurgical Analysis of Post-Test Fatigue and Creep-Fatigue Specimens}

Metallurgical analysis of the failed fatigue and creep-fatigue specimens was first performed using optical microscopy to obtain a description of the macroscopic behavior. SEM analysis was conducted on selected specimens to document the oxidation present at the specimen surface and crack surfaces and to determine whether creep cavitation was present. This detailed metallurgical work was performed on a subset of the specimens; the fatigue specimens and the creep-fatigue specimens with a 10 minute hold period tested at $600^{\circ} \mathrm{C}$ and $650^{\circ} \mathrm{C}$. This subset offered a comparison of the fatigue and creep-fatigue failure mechanism/s as well as information on the influence of temperature.

\subsection{Stainless Steel}

The 316 fatigue specimen cycled at $1 \%$ total strain and $600^{\circ} \mathrm{C}$ exhibited a single large macrocrack as well as finer cracking throughout the gage section, as shown in Figure 12(a) and (b). The specimen surface had a well adhered oxidation product. Optical microscopy of a face parallel to the stress axis and perpendicular through the largest macrocrack revealed multiple fine cracks that extended to a depth of several hundred microns into the specimen. These cracks, shown in Figure 12(c) and (d), were transgranular and appeared to have a thin oxide layer on the surface; extensive environmental damage was not observed in the cracks. The image of the large macrocrack in Figure 12(e) shows the thin oxide layer on the crack surface. The comparable 316 creep-fatigue specimen, tested at $600^{\circ} \mathrm{C}$ and $1 \%$ total 


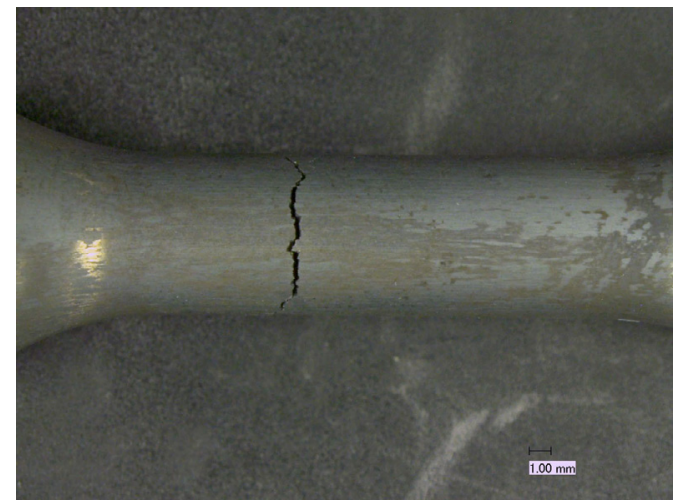

(a)

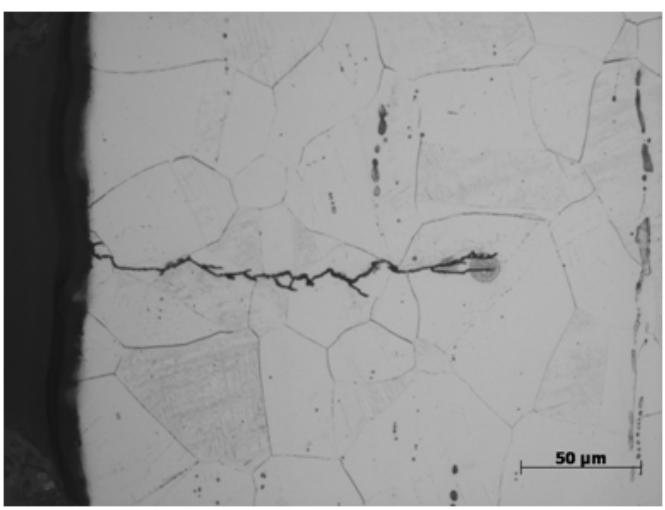

(c)

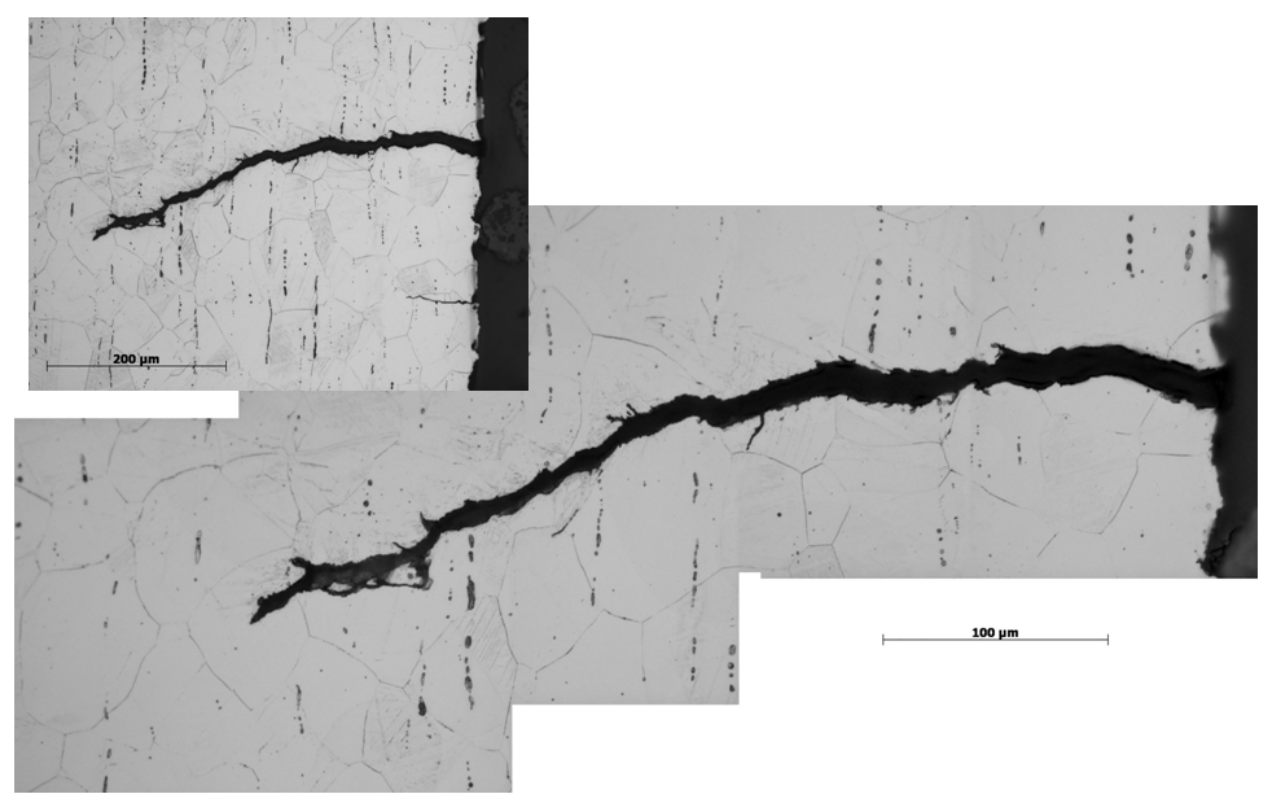

(d)

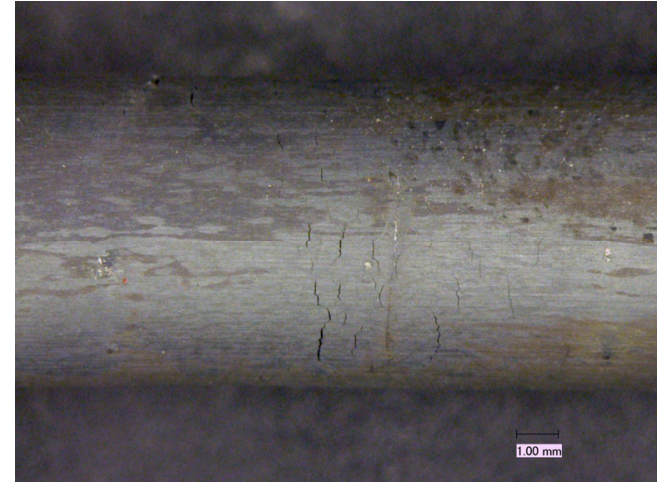

(b)

d)

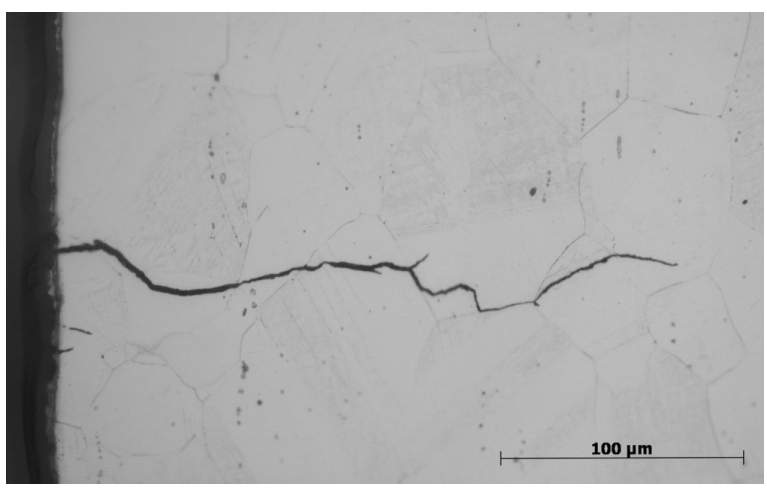




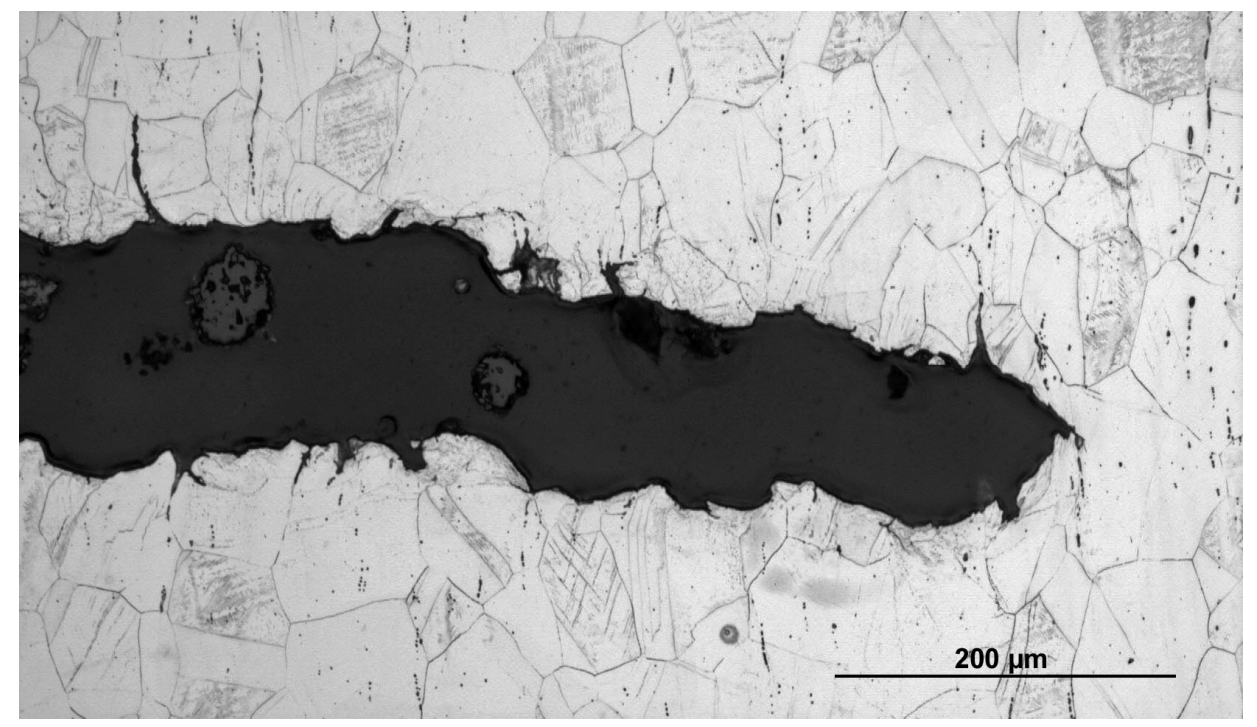

(e)

Figure 12. A 316 stainless steel fatigue specimen after testing at $600^{\circ} \mathrm{C}$ and a $1 \%$ total strain. A large crack as well as multiple finer cracks and discoloration due to environmental damage are visible on the specimen surface (a) and (b). Longitudinal imaging reveals that the fine cracks are several grain diameters in depth and typical start transgranularly and propagate in a transgranular manner (c) and (d). The large macrocrack is shown in (e).

strain range and a 10 minute hold at peak tensile strain, is shown in Figure 13. From the specimen surface, the failed 316 stainless steel creep-fatigue specimen appears similar to the fatigue specimen. However, the cracking in the creep-fatigue specimen appears to initiate intergranularly and significantly more oxidation is present along the crack surface, visible in Figure 13(c) and Figure 13(e), respectively. Crack propagation is in a predominately transgranular manner, although intergranular cracking is present, as evidenced in Figure 13(d) and (e). There was no evidence of creep cavitation on the grain boundaries in the bulk of the material. Comparison of the optical micrographs in Figure 12(c), (d), and (e) to Figure 13(c), (d), and (e) clearly shows that additional environmental damage has occurred during creepfatigue cycling relative to the continuous cycle fatigue. The thicker oxide layer is consistent with the increased time at temperature, approximately 250 hours, experienced by the creep-fatigue specimen.

Significantly more oxide is also present in the fatigue and creep-fatigue specimens of 316 stainless steel tested at the higher temperature, $650^{\circ} \mathrm{C}$. The cracks are filled with oxide and there is greater separation between the crack flanks, as shown for the fatigue specimen in Figure 14 and Figure 15 and the creep-fatigue specimen in Figure 16. The oxide-filled cracks extend several grain diameters in depth from the specimen surface. Branching is observed along the cracks and is particularly common at intersecting grain boundaries, as shown in Figure 14(b) and (c), although the crack continues to propagate in a transgranular manner despite the branching at oxidized grain boundaries. SEM images in Figure 15 reveal a higher magnification view of the oxide/s present in the crack. The cracks appear to contain at least two types of oxide. The oxide (labeled 1) nearest to the base metal extends along the outer surface of the crack and is rich in both $\mathrm{Cr}$ and $\mathrm{Fe}$ but also contains a significant amount of $\mathrm{Ni}$. A more porous oxide (labeled 2 ) is present in the inner region of the crack and appears to be sandwiched between the outer oxide layers. The inner oxide is Fe-rich with relatively low amounts of both $\mathrm{Cr}$ and $\mathrm{Ni}$. A small amount of $\mathrm{Mn}$ is present in both oxides, but little $\mathrm{Si}$ or Mo is present. 


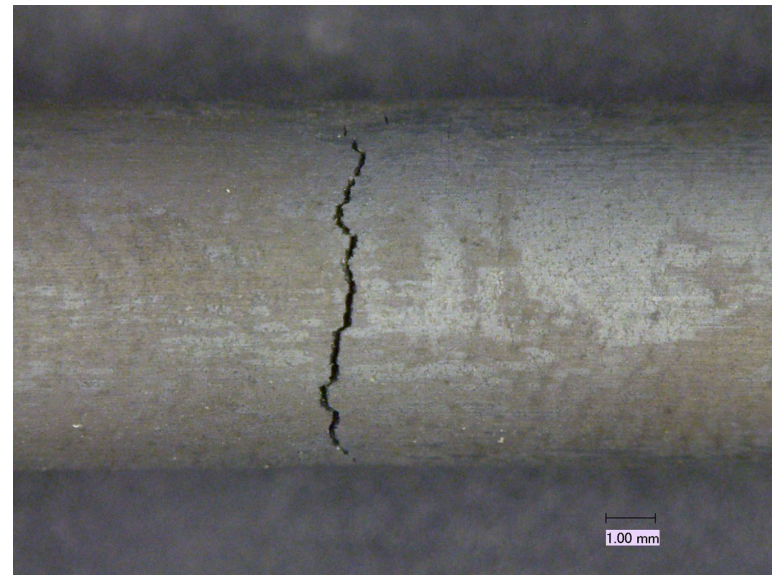

(a)

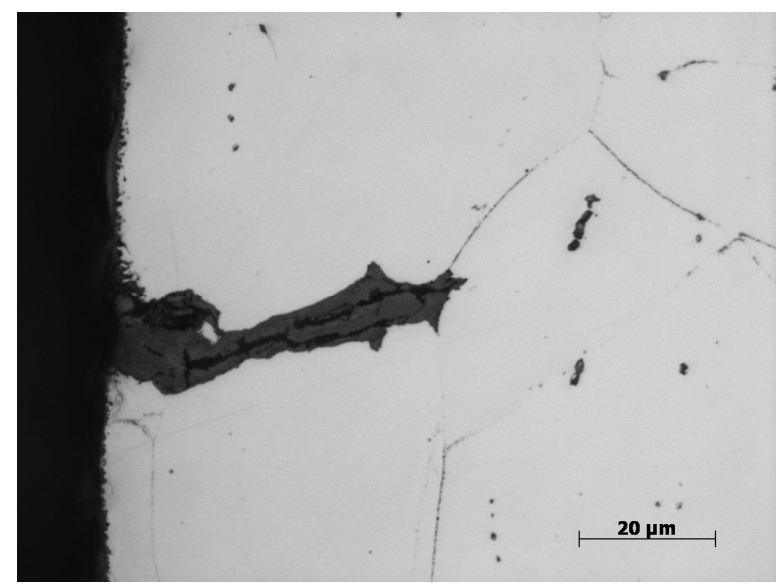

(c)

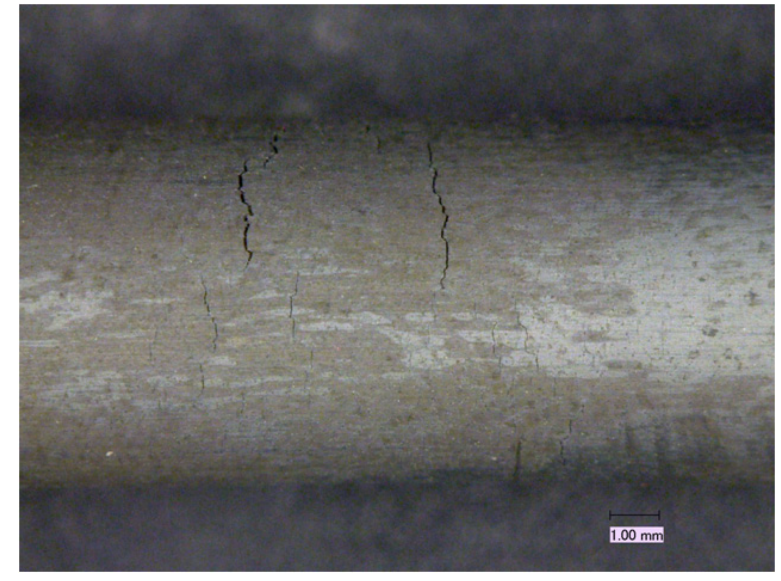

(b)

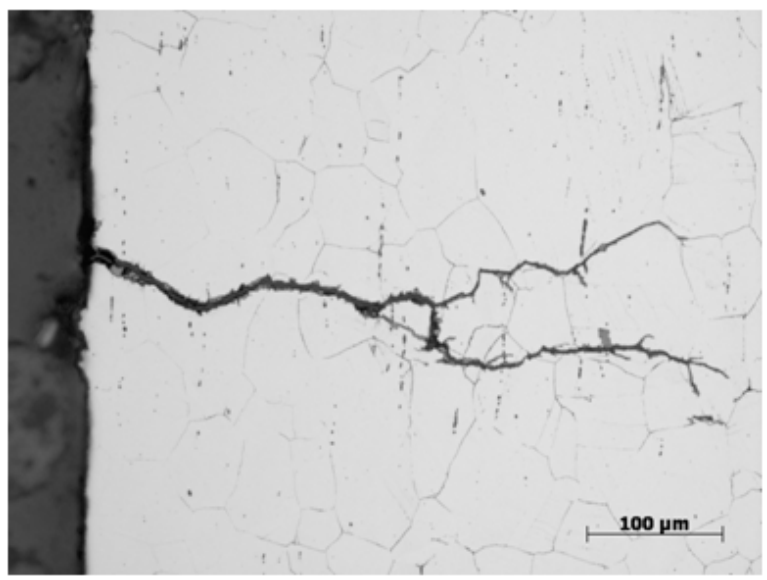

(d)

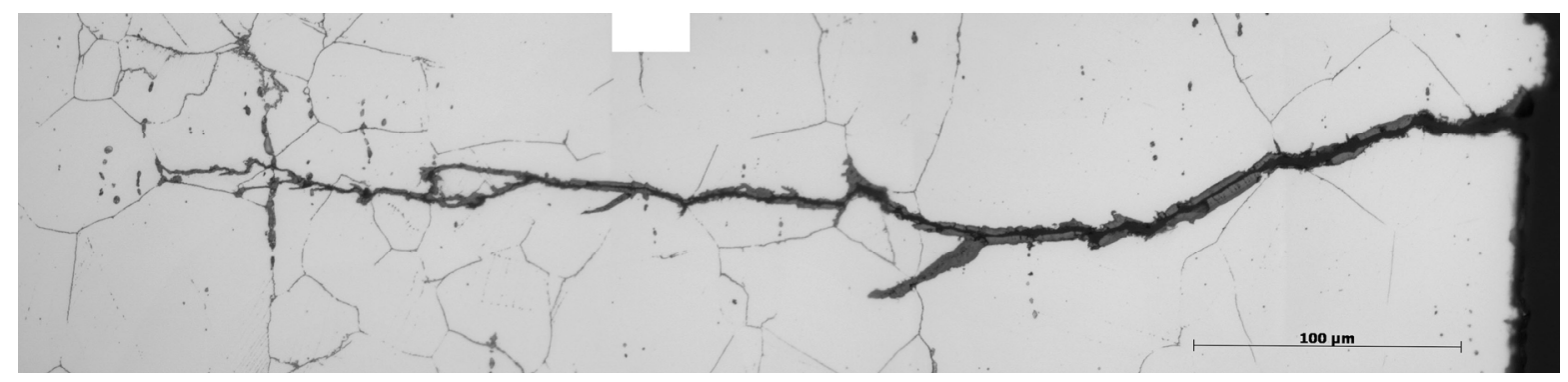

(e)

Figure 13. A 316 stainless steel creep-fatigue specimen after testing at $600^{\circ} \mathrm{C}, 1 \%$ total strain, and a 10 minute hold time at peak tensile strain. A large crack as well as multiple finer cracks and discoloration due to environmental damage are visible on the specimen surface (a) and (b). Longitudinal images reveal that the fine cracks are many grain diameters in depth and typical start intergranularly and propagate in a transgranular manner (c) and (d) and (e). 


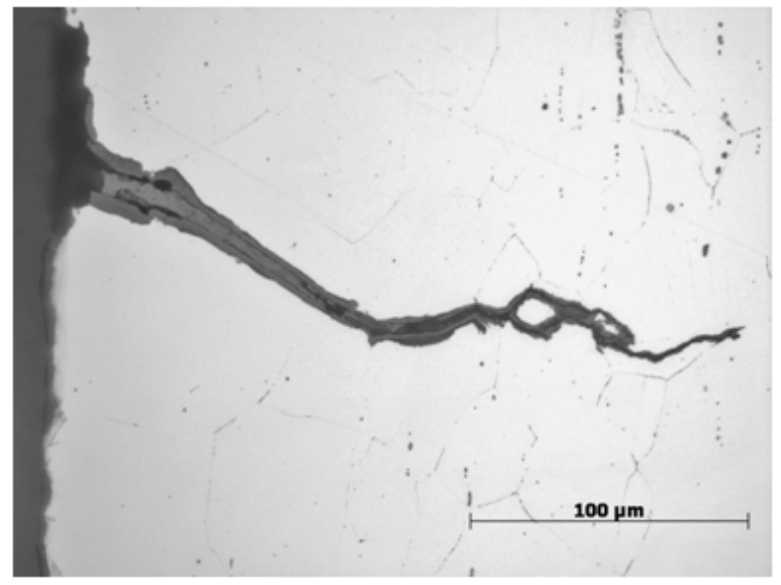

(a)

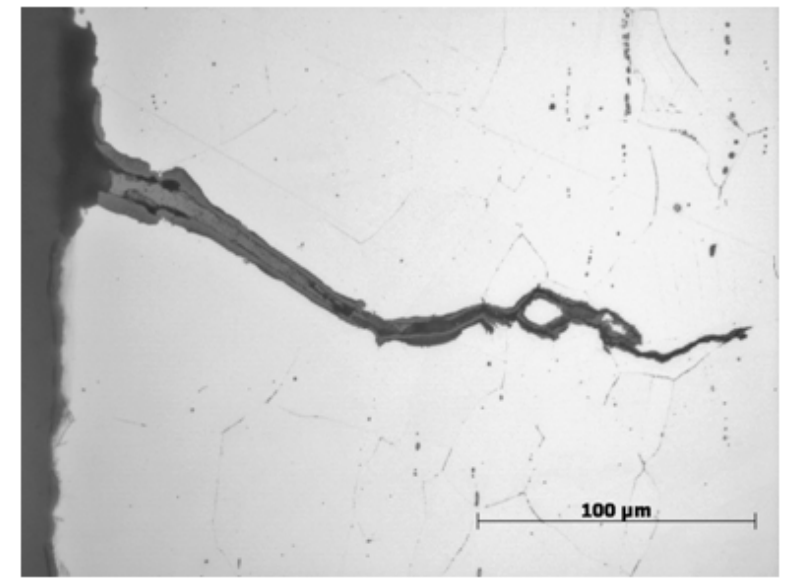

(b)

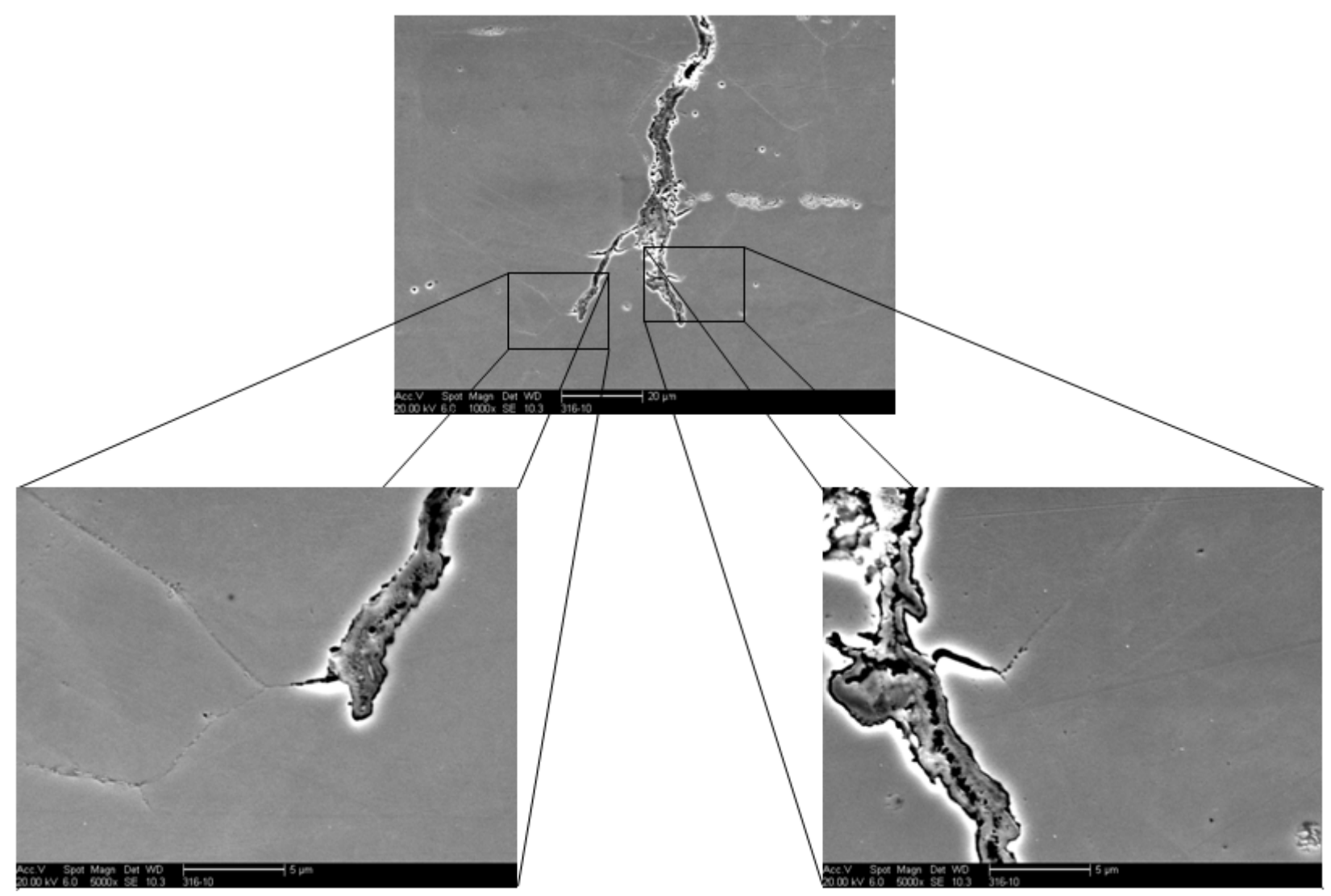

(c)

Figure 14. A 316 stainless steel fatigue specimen after testing at $650^{\circ} \mathrm{C}$ and a $1 \%$ total strain. Longitudinal images reveal that the fine cracks are several grain diameters in depth and typical start intergranularly and propagate in a predominately transgranular manner (a) and (b), despite the presence of small branches at intersecting grain boundaries. There is a significant amount of oxidation visible in the crack (c). 


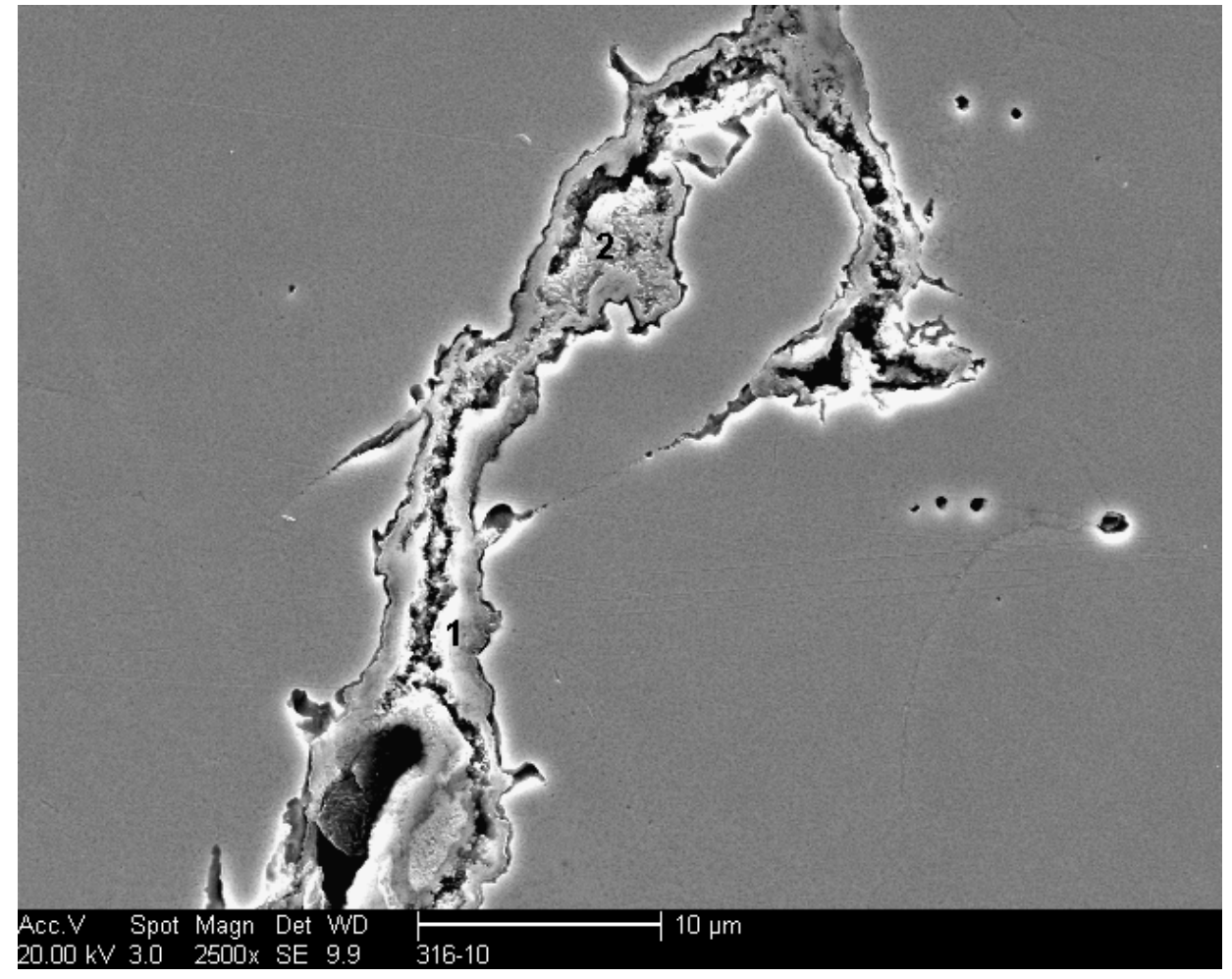

(a)

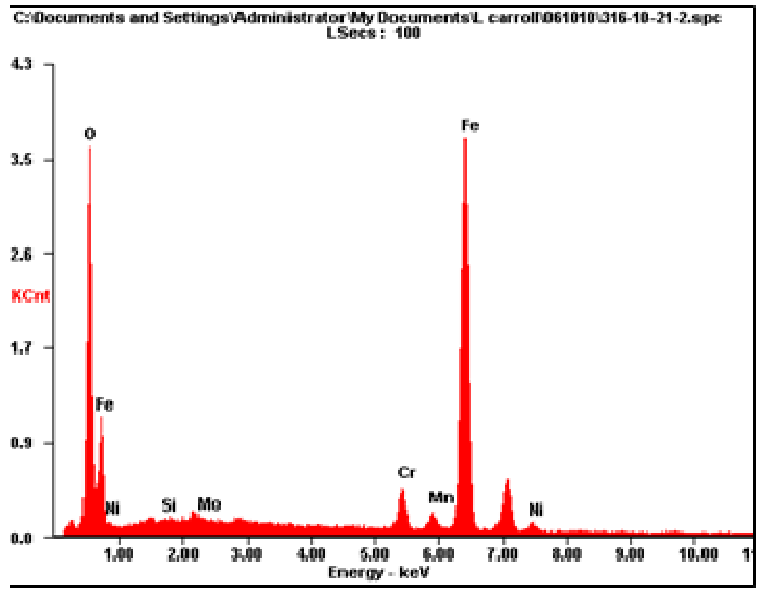

(b)

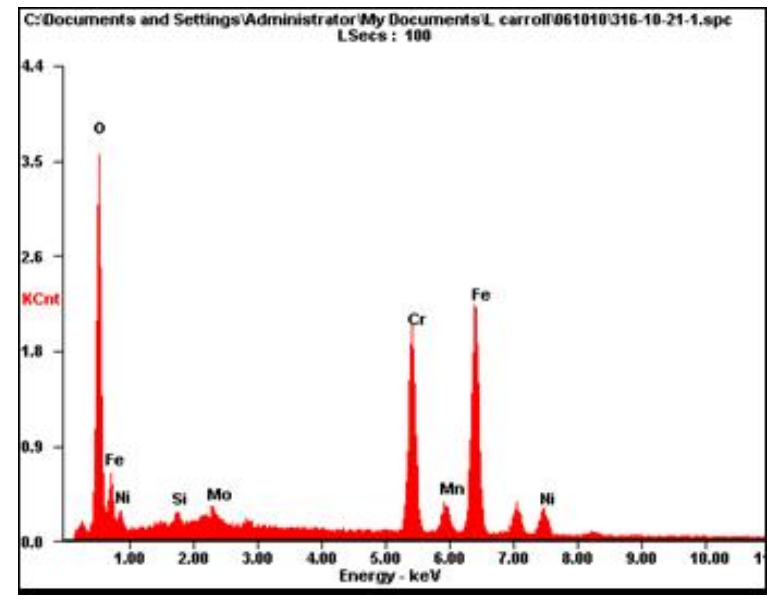

(c)

Figure 15. Oxide in the crack of a 316 stainless steel fatigue specimen after testing at $650^{\circ} \mathrm{C}$ and a $1 \%$ total strain. The number " 1 " and " 2 " in (a) correspond to the EDS spectra in (b) and (c), respectively. 


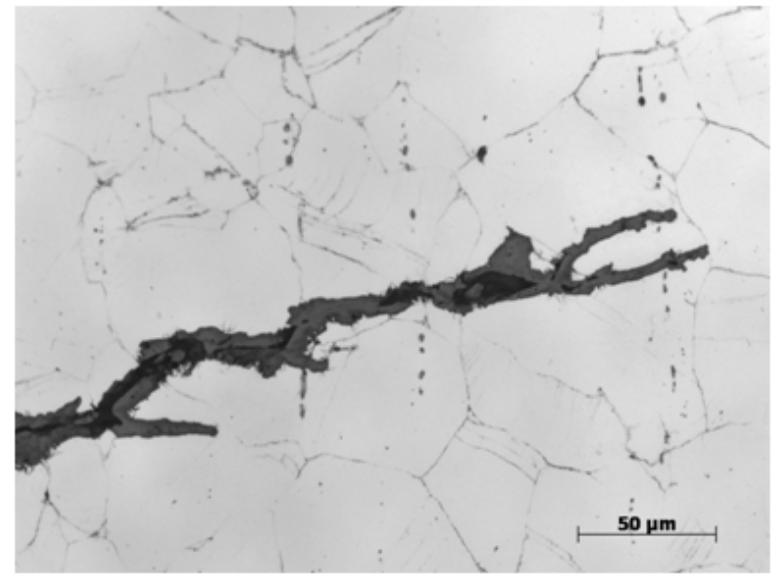

(a)

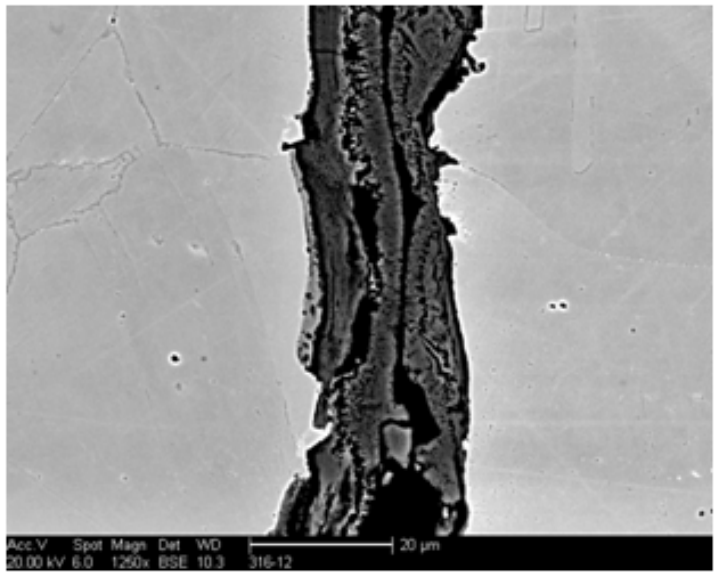

(b)

(c)

Figure 16. A 316 stainless steel creep-fatigue specimen after testing at $650^{\circ} \mathrm{C}, 1 \%$ total strain, and a 10 minute hold. Longitudinal images reveal that the fine cracks extend several grain diameters in depth from the specimen surface and typical start intergranularly and propagate in a predominately transgranular manner (a) and (b), despite the presence of small branches at intersecting grain boundaries. There is a significant amount of oxide visible in the crack (c). 
The creep-fatigue cycled specimen also showed an increased amount of oxide present on the specimen surface and the crack surface. A thick oxide layer on the order of 10 to $20 \mu \mathrm{m}$ is observed along the crack surface in Figure 16(a). Figure 16(b) shows the oxide is composed of multiple layers/oxides in a widely opened crack. Oxide is observed to be protruding from the cracks along the length and multiple short oxide filled cracks are present along the specimen surface. These cracks are depicted in a SEM image in Figure 17(a) in addition to their relationship to the surface oxide. The surface oxide layer is

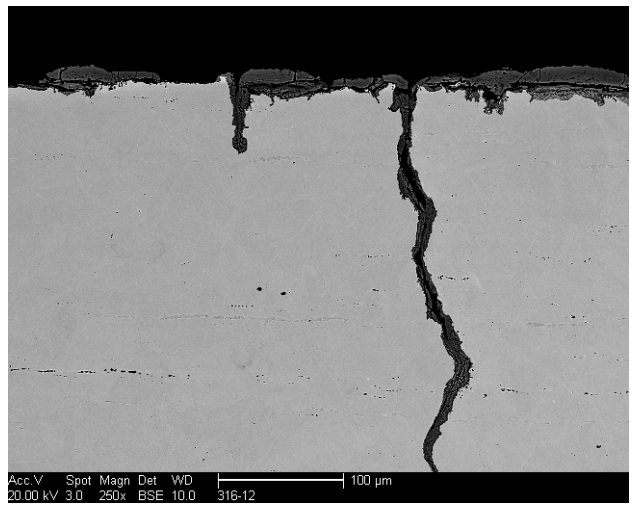

(a)

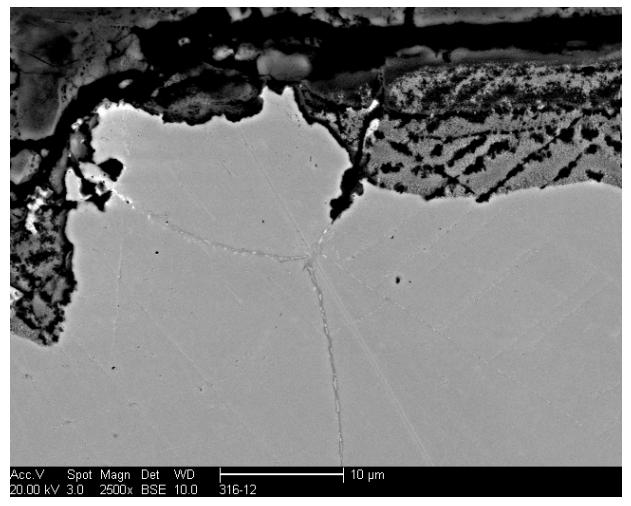

(c)

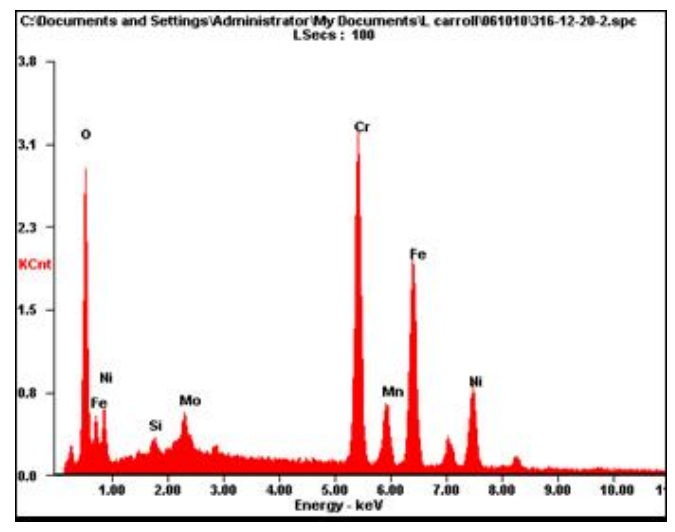

(e)

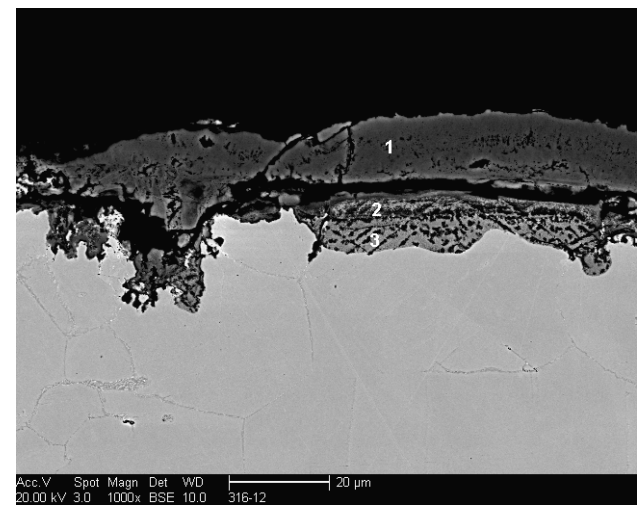

(b)

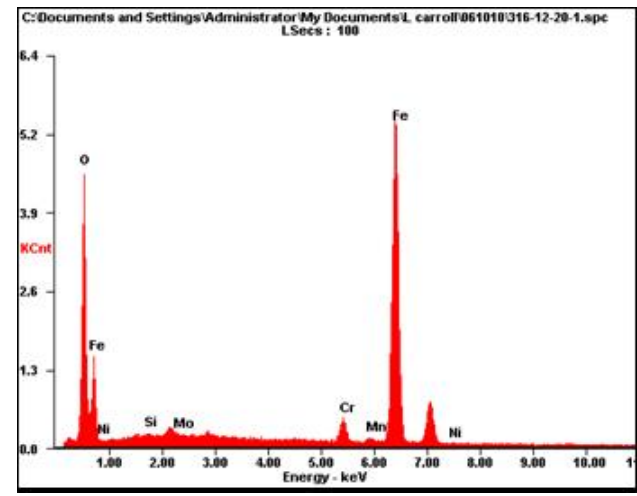

(d)

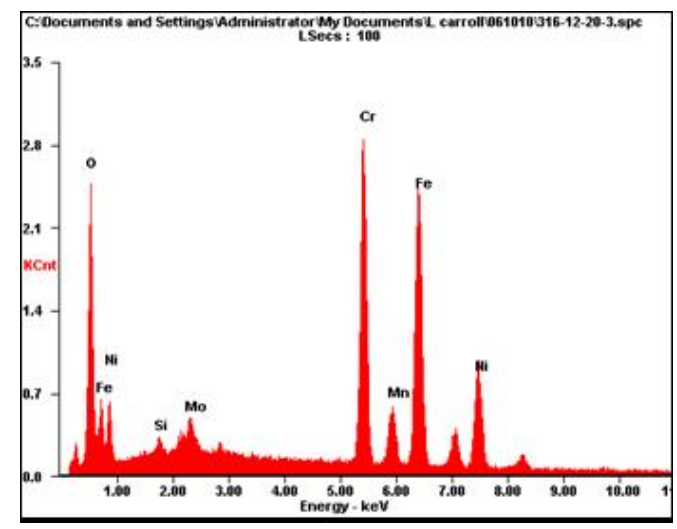

(f)

Figure 17. The surface of a 316 stainless steel creep-fatigue specimen after testing at $650^{\circ} \mathrm{C}, 1 \%$ total strain, and a 10 minute hold (a), (b), and (c). A SEM image illustrating the cracking and its relationship to the surface oxide (a). Higher magnification images of the surface oxide remaining on the specimen surface after mounting, polishing, and etching (b) and (c). The EDS spectra for the outer oxide 1 (d), 2 (e), and 3 (f) as labeled in (b). 
wavy and protrudes to different depths along the specimen surface, is approximately 30 to $40 \mu \mathrm{m}$ in thickness, and consists of a multi-layer oxide structure. The outer most surface oxide layer is predominately Fe rich with low levels of $\mathrm{Cr}$ present (labeled 1). The middle and inner surface oxide (labeled 2 and 3) are rich in $\mathrm{Fe}, \mathrm{Cr}$, and $\mathrm{Ni}$. There is a substantial amount of Ni present, approximately 15$20 \mathrm{wt} \%$, and some Mn approximately $3 \mathrm{wt} \%$. It is not possible to differentiate the compositions of the oxide labeled 2 and 3, nor determine if there is a structural difference without further analytical techniques. Also these oxide layers exhibit two distinctly different contrasts, determination of the individual constituents, if present, was not attempted with SEM EDS. Again, there was no evidence of grain boundary cavitation, similar to the creep-fatigue tested specimen at $600^{\circ} \mathrm{C}$.

TEM observations from the gage section of a 316 creep-fatigue specimen tested at $650^{\circ} \mathrm{C}$ with a $1.0 \%$ total strain range and 5 minute tensile hold. TEM micrographs in Figure 18 clearly show the formation of an equiaxed cellular dislocation structure. These dislocation microstructures consist of cell walls with large dislocation densities and cell interiors which are relatively free of dislocations. Furthermore, the cell interiors in these substructures contain a very low density of second phase particles. There is also evidence that the dislocation substructure has partly annealed during creep-fatigue testing due to the climb of dislocations and their subsequent rearrangement. Figure 18(a) shows possible rearrangement of dislocations in the cell walls into more orderly structures. These boundaries contrast the relatively narrow walls shown in the structure in Figure 18(b). In areas of the specimen which did not contain a defined cellular structure, a high density of dislocation tangles are present within the grains, as shown in Figure 19. Also shown are second phase particles along the grain boundary. The morphology of these particles indicates that they are most likely carbides of the $\mathrm{M}_{23} \mathrm{C}_{6}$ variety.

\subsection{HT-UPS Steel}

The HT-UPS specimen cycled in fatigue at $600^{\circ} \mathrm{C}$ and a $1 \%$ total strain is shown in Figure 20 . Fine cracks are observed along the outer specimen surface initiating and propagating in a transgranular manner. There is no oxide layer visible in the optical micrographs. The addition of a 10 minute hold time

results in a visible fine oxide layer along the crack surfaces. The secondary cracking is observed to initiate both intergranularly and transgranularly, and then propagates in a transgranular manner, as shown in detail in Figure 21. Similar crack propagation behavior was observed for fatigue and creep-fatigue of the HT-UPS alloy at $650^{\circ} \mathrm{C}$, shown in Figure 22 through Figure 25. Continuous cycling resulted in cracking initiating at the surface within a grain and creep-fatigue cycling resulted in cracking often initiating intergranularly, illustrated in Figure 22 and Figure 24. In both cases, crack propagation was transgranular.

The surface oxide and oxide formed along the crack surfaces are shown in SEM images for both the continuous cycle fatigue and the creep-fatigue test with a 10 minute hold in Figure 23 and 25, respectively. The surface oxide is approximately 1 micron in thickness for the fatigue specimen and 2 microns in thickness for the creep-fatigue specimen. A fine second phase has appeared to precipitate in the case of the creep-fatigue specimen, although this phase is too fine to analyze with the SEM. A small amount of oxide is observed in the cracks of the fatigued specimen and, not surprisingly, a thicker oxide is present in the cracks of the 10 minute hold creep-fatigue specimen. The oxide consists of two types, which are indicated by number in Figure 25(b). Similar to the 316 stainless steel, the oxides filling the cracks in the HT-UPS steel are an Fe-rich oxide that is sandwiched between a Fe-Cr rich oxide. Figure 25(c) clearly shows the oxide-filled crack having propagated initially along the grain boundary and then diverging from the boundary several hundred micron below the specimen surface. Also evident in the HT-UPS creep-fatigue specimen is the presence of small precipitates along the grain boundaries. Again, these precipitates are too small to analyze using SEM techniques.

TEM observation of the creep-fatigue specimen tested at $650^{\circ} \mathrm{C}, 1 \%$ total strain range, and 1 minute tensile hold time. Similar to the 316 stainless steel, precipitation of larger $\mathrm{M}_{23} \mathrm{C}_{6}$ carbides on the grain boundaries is observed in the HT-UPS material, as shown in Figure 26. However, a number of 
microstructural observations in this material contrast those in 316 stainless steel. The first difference is the presence of a relatively high density of $(\mathrm{Nb}, \mathrm{Ti}, \mathrm{V}) \mathrm{C}$ which have precipitated within the grains during deformation, shown in Figure 27. This is an expected observation as the alloy contains additions of $\mathrm{Nb}$, $\mathrm{Ti}$, and $\mathrm{V}$ to form nanometer-sized particles to pin dislocations during plastic deformation. The micrographs shown in Figure 28 clearly illustrate the pinning of dislocations by second phase particles during high temperature deformation. A second difference between the two steels likely results from this dispersion of MC carbides in the HT-UPS material. In 316 stainless steel, there are less obstacles to dislocation motion and therefore the dislocations are more mobile and able to arrange themselves into orderly low energy configurations due to the lack of fine second phase intragranular particles. In the HTUPS material, however, at these conditions a cellular substructure within the grains is not formed likely due to the lack of dislocation mobility.

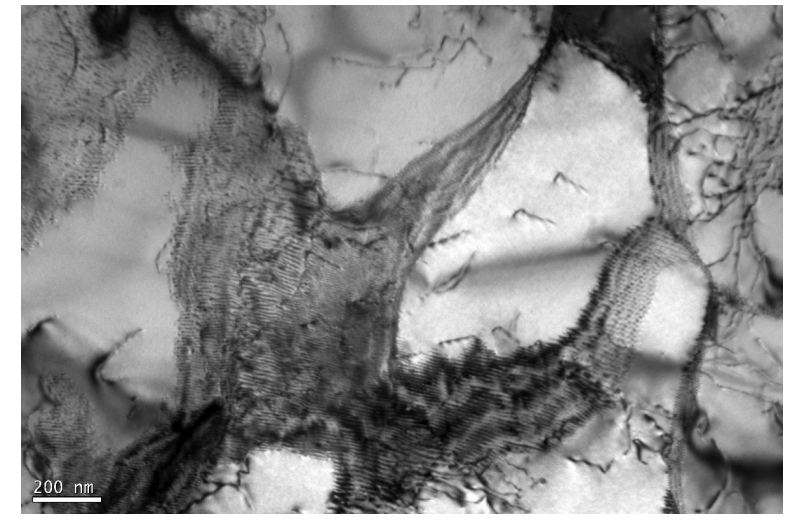

(a)

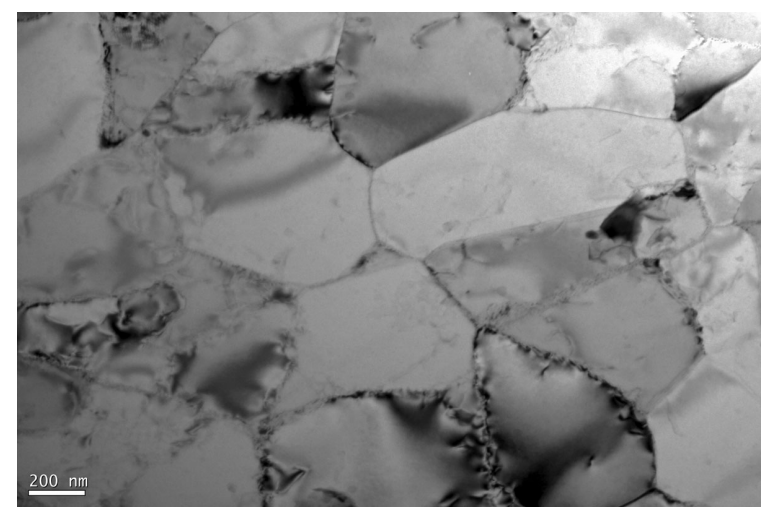

(b)

Figure 18. TEM bright field micrographs of 316 stainless steel after creep-fatigue testing showing the dislocation arrangements and cellular pattern (a) and the fine equiaxed substructure (b) which emerges.

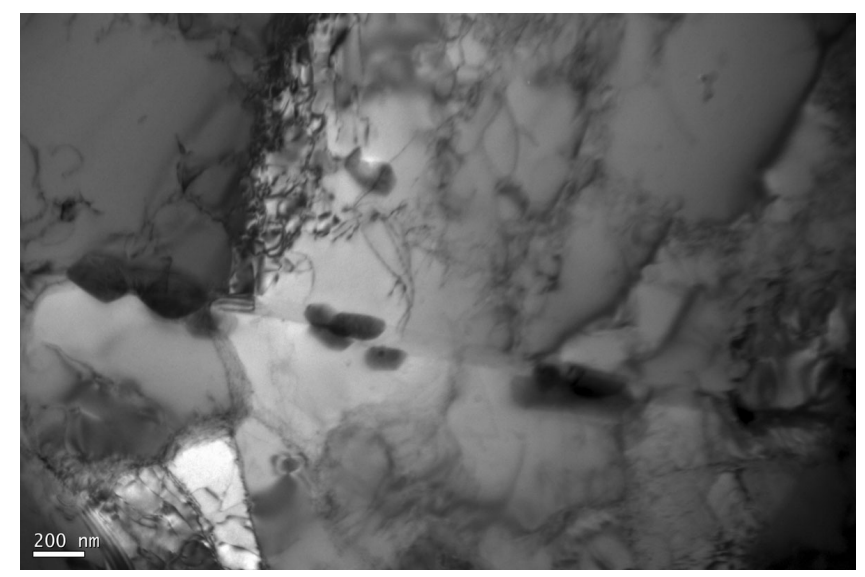

Figure 19. A 316 creep-fatigue specimen showing grain boundary carbides, likely $\mathrm{M}_{23} \mathrm{C}_{6}$, and dislocation tangles within the grains. 


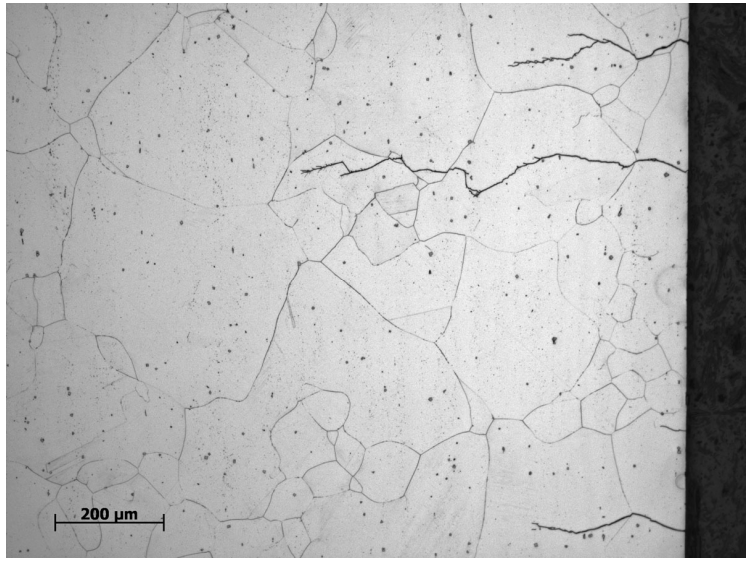

(a)

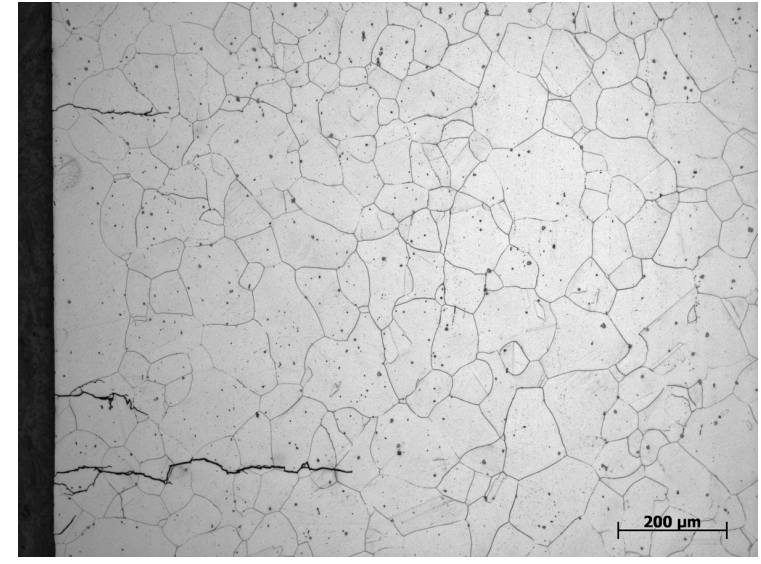

(b)

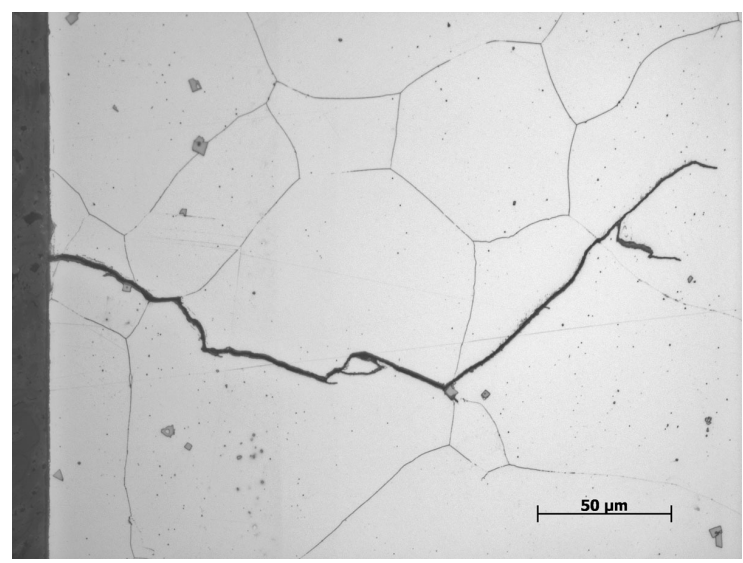

(c)

Figure 20. Optical micrographs of a HT-UPS specimen after fatigue deformation at $600^{\circ} \mathrm{C}$ and $1 \%$ total strain. 


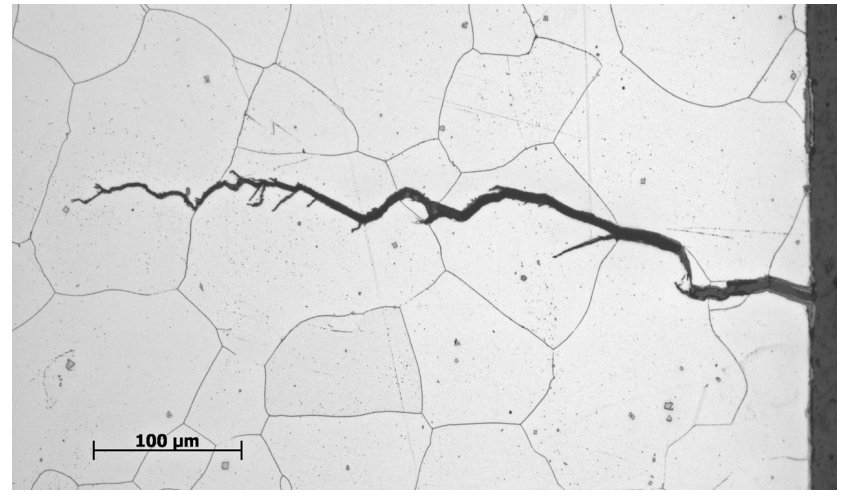

(a)

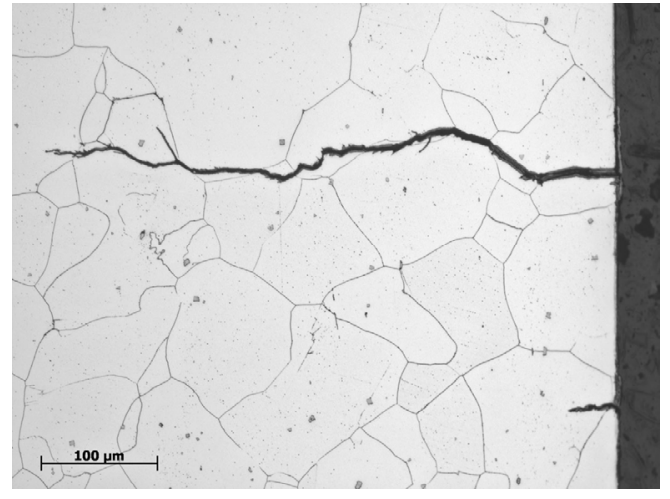

(b)

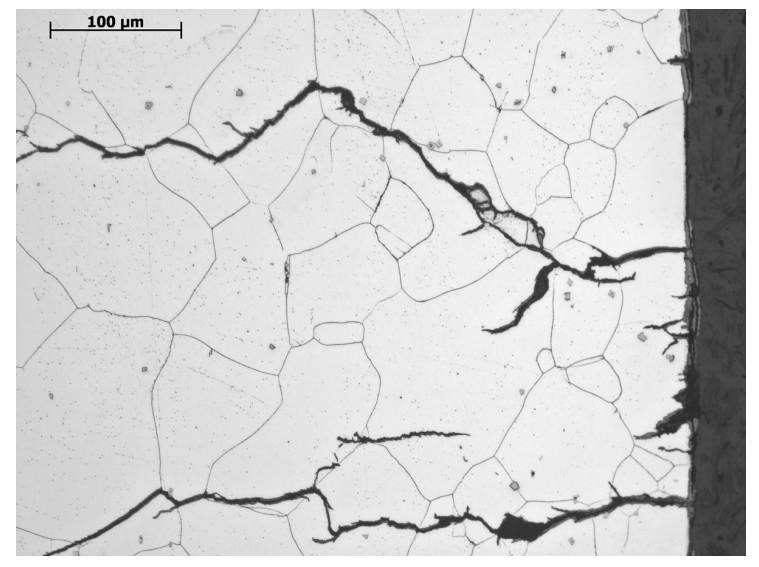

(c)

Figure 21. Optical micrographs of a HT-UPS specimen after creep-fatigue deformation at $600^{\circ} \mathrm{C}$, 10 minute hold, and a $1 \%$ total strain. Cracks are observed to initiate both intergranularly (a) and transgranularly (b). Crack paths are independent of grain boundaries, propagating in a transgranular manner. 


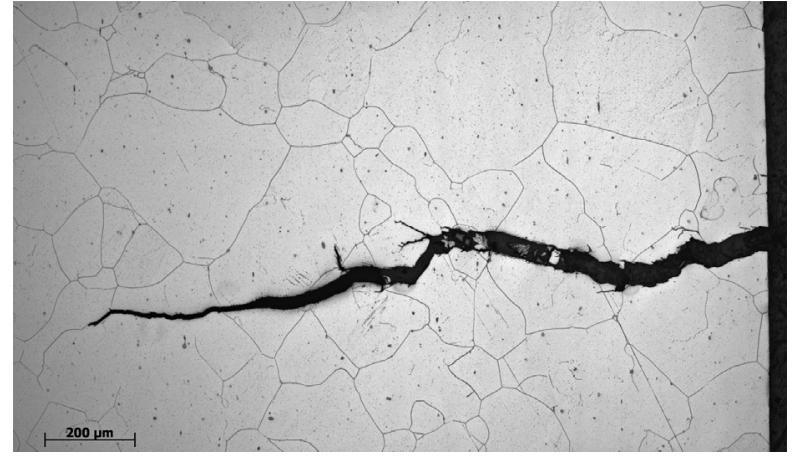

(a)

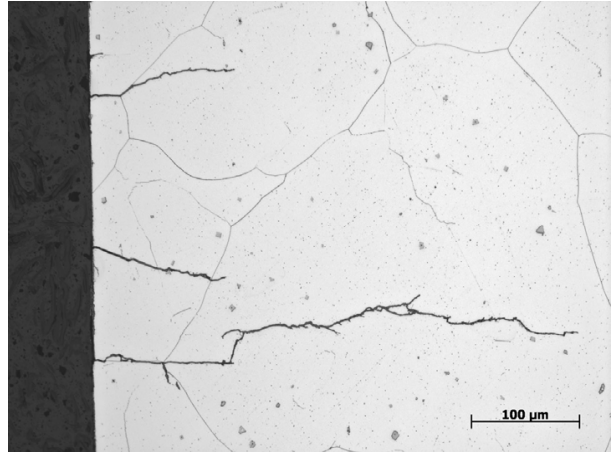

(b)

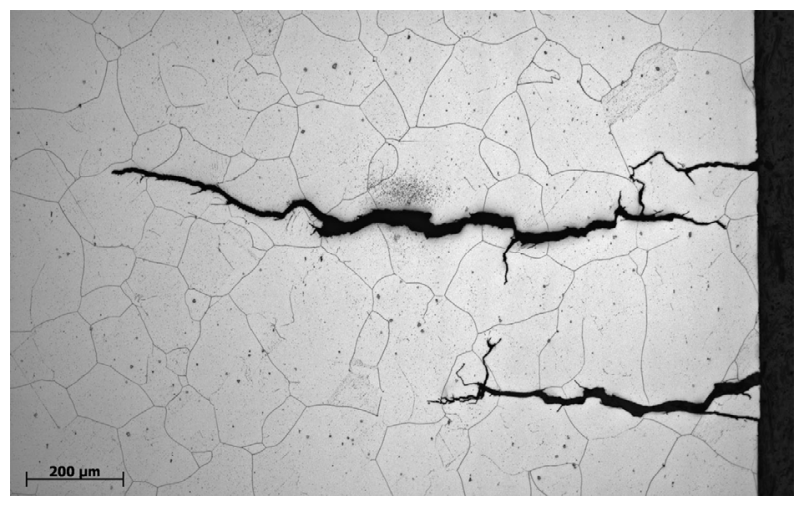

(c)

Figure 22. Optical micrographs of a HT-UPS specimen after fatigue deformation at $650^{\circ} \mathrm{C}$ and a $1 \%$ total strain. Cracks are observed to initiate and propagate transgranularly.

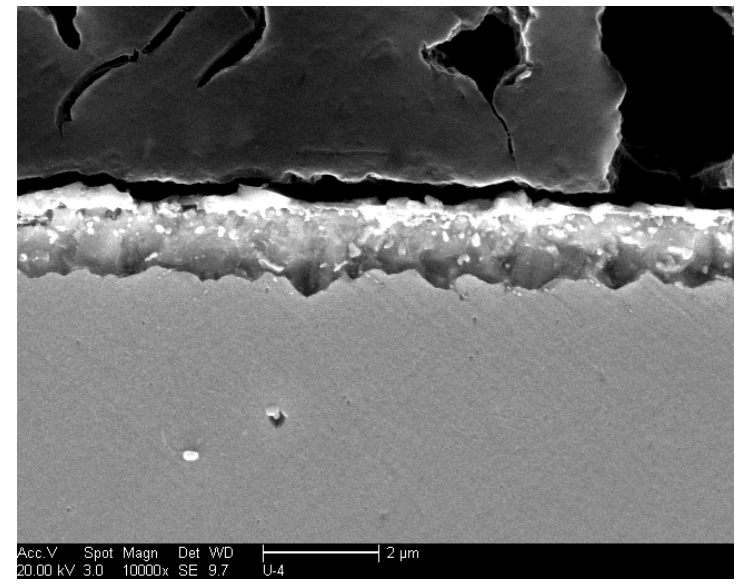

(a)

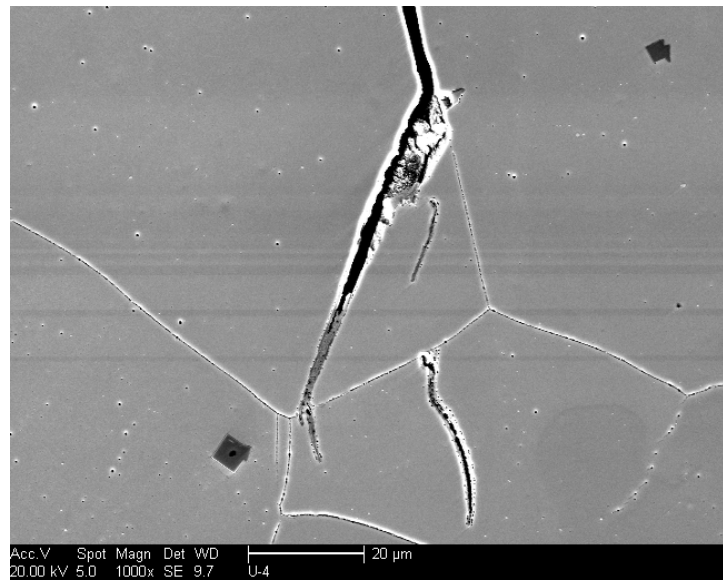

(b)

Figure 23. SEM micrographs of a HT-UPS specimen after fatigue deformation at $650^{\circ} \mathrm{C}$ and a $1 \%$ total strain. The surface oxide is shown in (a) and an oxide-filled tip of a secondary crack is shown in (b). 


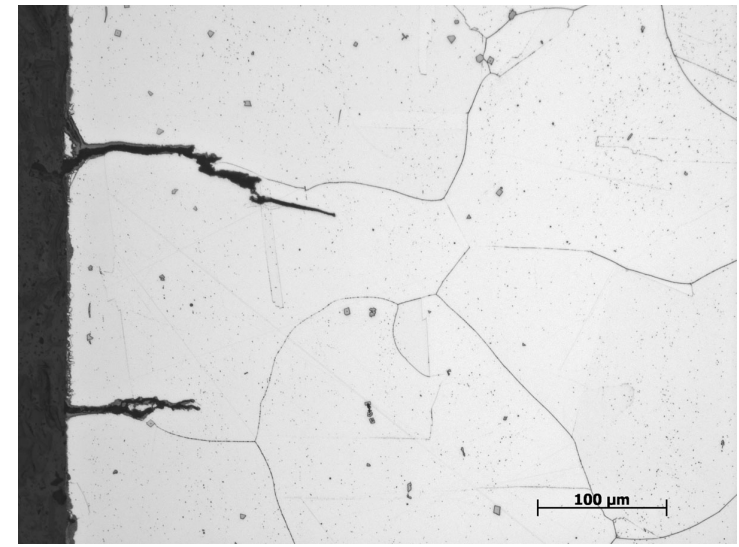

(a)

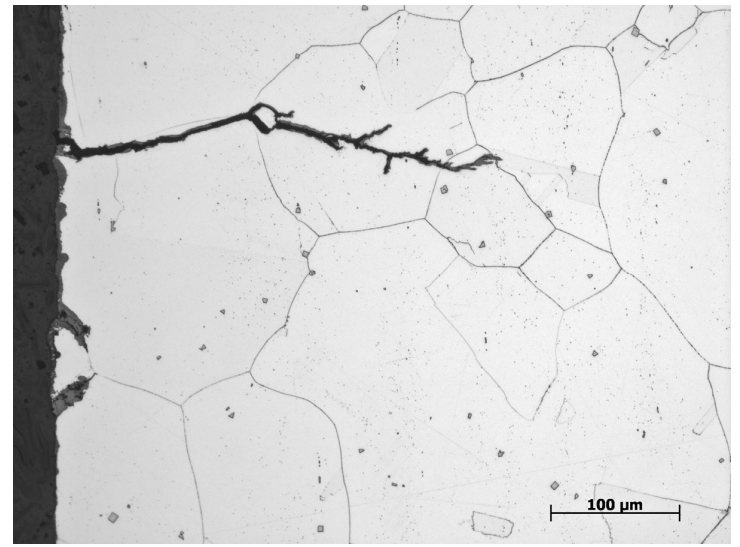

(b)

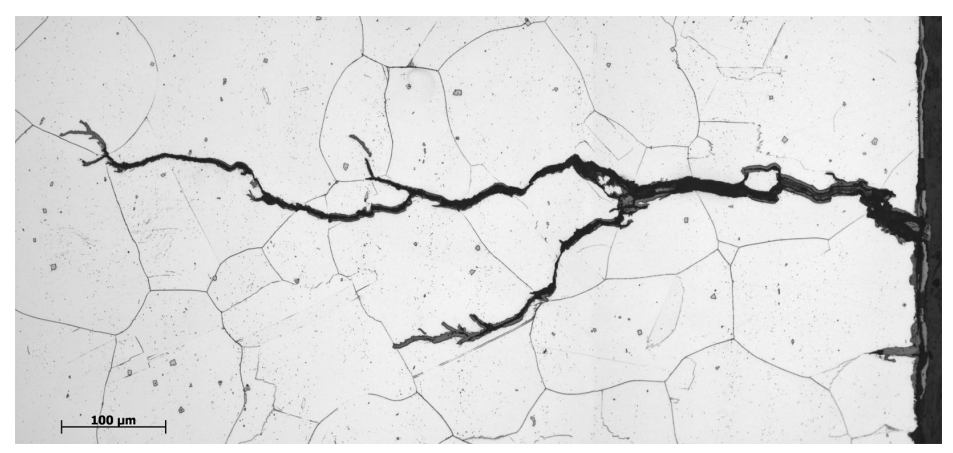

(c)

Figure 24. Optical micrographs of a HT-UPS specimen after fatigue deformation at $650^{\circ} \mathrm{C}, 10$ min hold, and a $1 \%$ total strain. Cracks are observed to initiate intergranularly and propagate in a transgranular manner. 


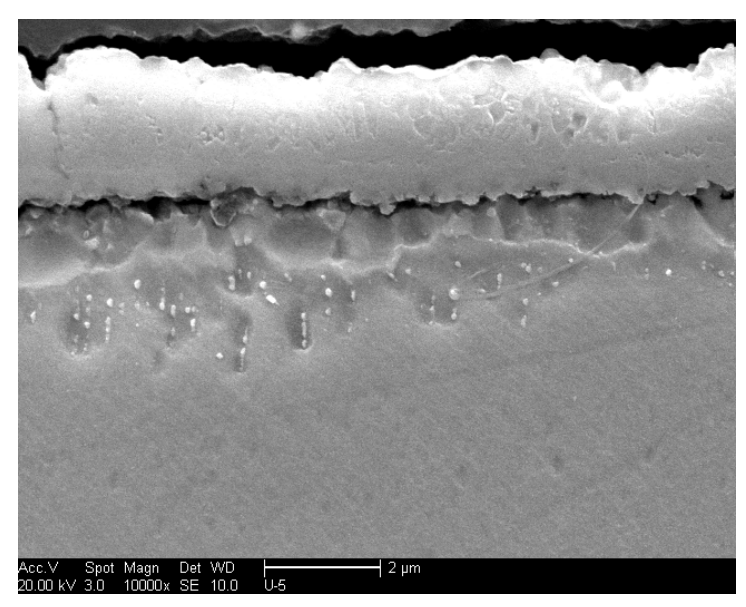

(a)

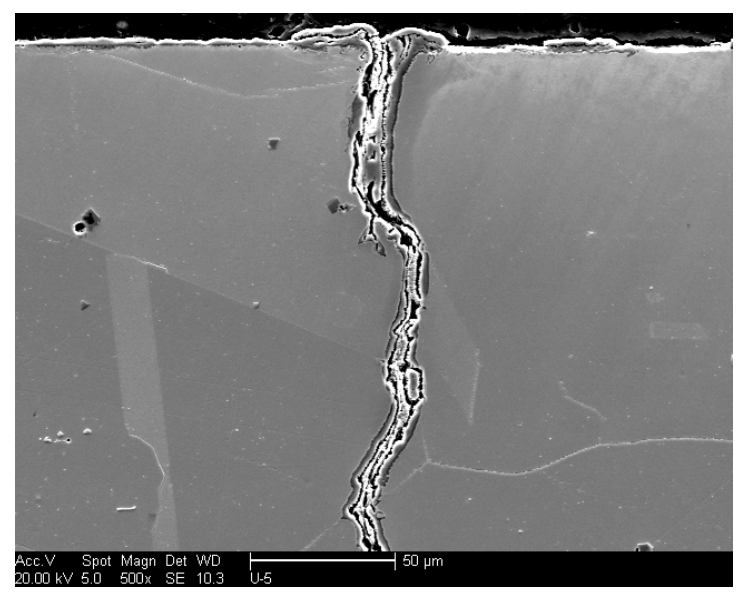

(c)

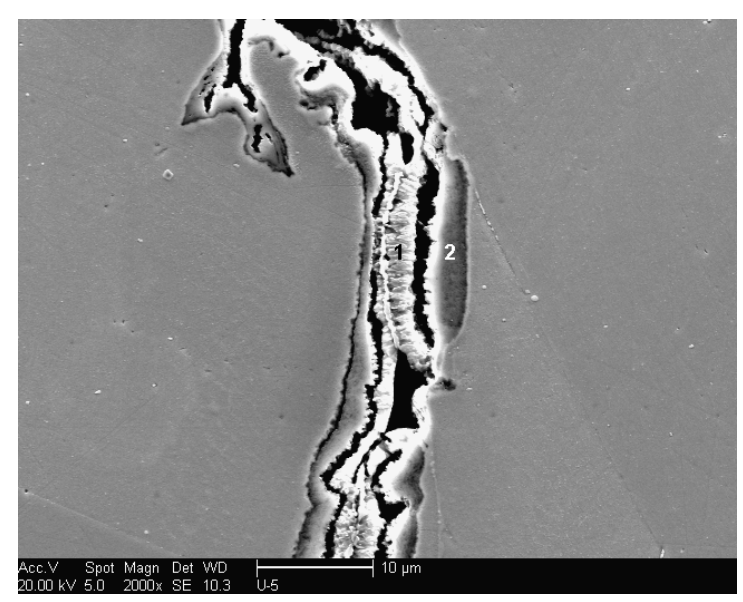

(b)

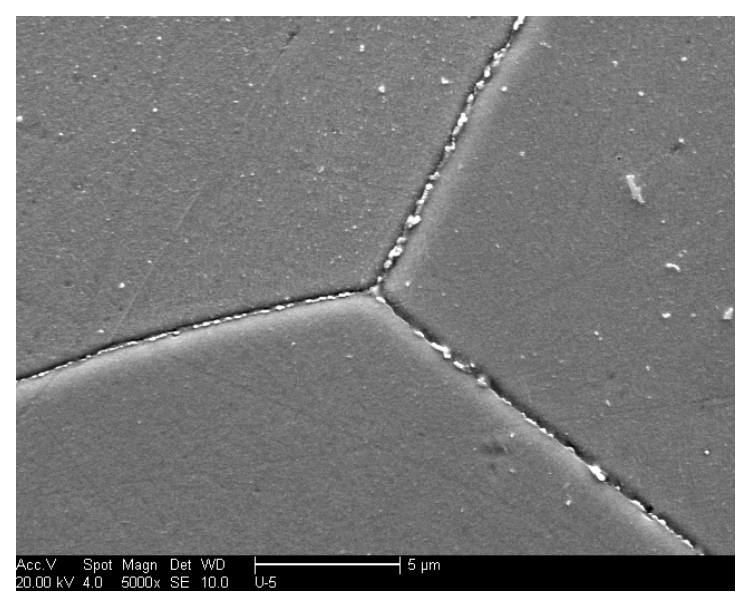

(d)

Figure 25. SEM micrographs of a HT-UPS specimen after fatigue deformation at $650^{\circ} \mathrm{C}, 10 \mathrm{~min}$ hold, and a $1 \%$ total strain. An oxide that has formed on the specimen surface is shown in (a) and oxide-filled cracks are shown in (b) and (c). Fine precipitates are present on the grain boundaries (d).

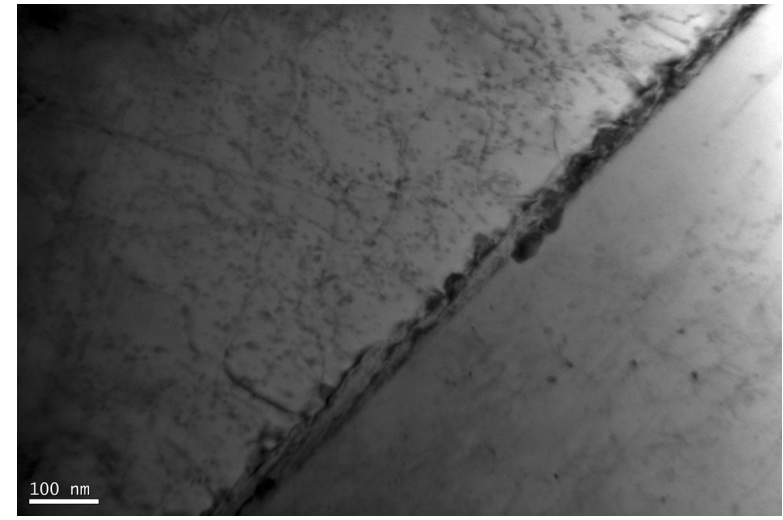

(a)

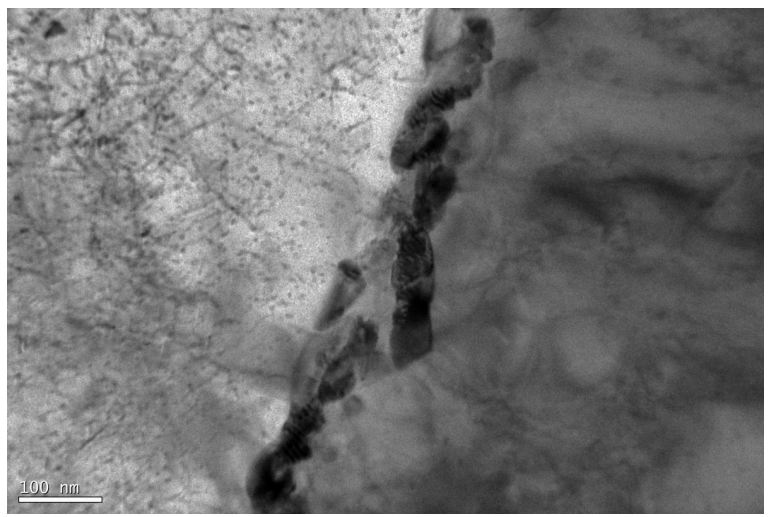

(b)

Figure 26. TEM micrographs of second phase particles, likely $\mathrm{M}_{23} \mathrm{C}_{6}$ carbides, which have precipitated on grain boundaries in the post creep-fatigue HT-UPS material. 


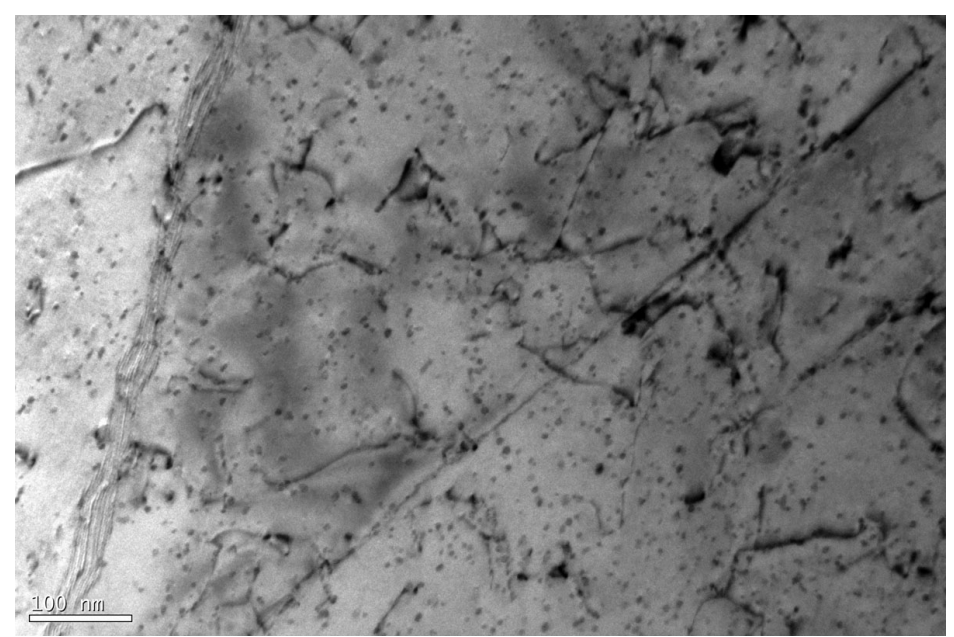

Figure 27. TEM micrograph of HT-UPS stainless steel showing nanometer sized MC carbides within the grains after creep-fatigue testing.

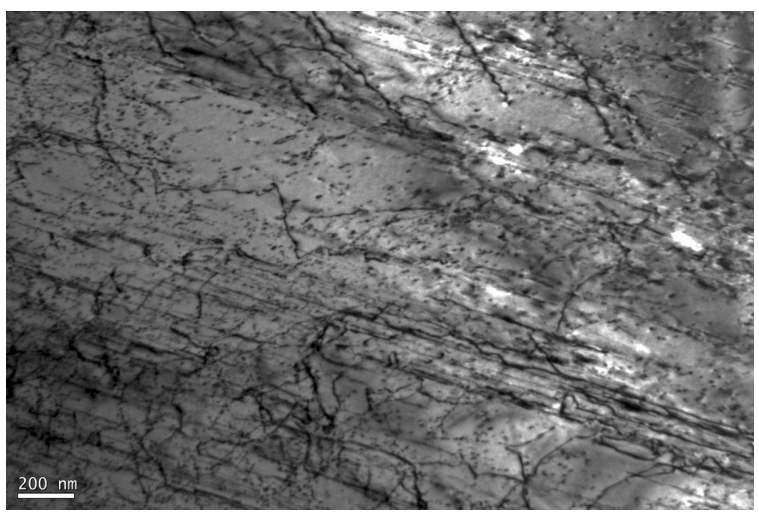

(a)

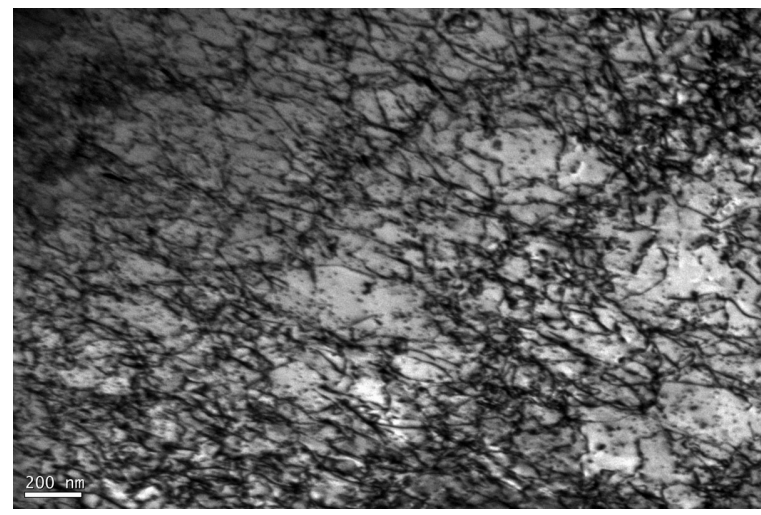

(b)

Figure 28. Dislocations pinned within the grains by the large percentage of MC carbides in HT-UPS material. 


\section{DISCUSSION}

Despite different responses to cyclic loading, the creep-fatigue lives of the HT-UPS steel and the stainless steel were similar. The 316 stainless steel exhibited almost no cyclic hardening, whereas the HT-UPS peak cyclic stresses were initially low and then extensive cyclic hardening was observed, as shown in Figure 8 and 9. This is consistent with the condition in which each of the materials was tested and the characterization of the base material microstructure. The 316 stainless steel was tested in the annealed, cold drawn condition, whereas the HT-UPS steel was tested after hot rolling at $1200^{\circ} \mathrm{C}$. Second phase precipitates were absent in the HT-UPS as-received material but formed during creep-fatigue deformation. This is evident from the TEM images of the as-received HT-UPS material and the post creep-fatigue deformed material in which an absence of second phase precipitates and a relatively low density of dislocations was observed in the base material, shown in Figure 5. Dislocations are introduced into the microstructure during creep-fatigue deformation, likely introduced as plastic strain accumulated during the first creep-fatigue cycle. These dislocations enable the precipitation of nano-scale MC carbides, which clearly precipitated during testing, shown in Figure 27. The cyclic hardening observed in the HT-UPS steel, shown in Figure 8 and 9, was at least in part due to the formation of these nano-scale $(\mathrm{Nb}, \mathrm{Ti}, \mathrm{V}) \mathrm{C}$ carbides obstructing dislocation motion. However, despite the decreased dislocation mobility in the HT-UPS material the creep-fatigue life or number of cycles to failure was not significantly different than the conventional 316 stainless steel.

Furthermore, the influence of cold work on the creep-fatigue life of 316 stainless steel is not entirely clear. There are several studies that suggest that prior cold work may enhance the creep-fatigue interaction and possibly decrease creep-fatigue life. Therefore it may be more likely that the 316 stainless steel would exhibit evidence of creep-fatigue interaction, however, this does not appear to be the case as the cracking at $600^{\circ} \mathrm{C}$ and $650^{\circ} \mathrm{C}$, at least up to the 10 minute hold time, was predominately transgranular. Evidence of grain boundary cavitation has not been observed, although, the expected cavitation is on the order of a micron and is difficult to differentiate from pitting due to etching. The higher crack growth rates reported for cold worked 316 stainless steel have been attributed to a shift from transgranular to intergranular cracking. The absence of intergranular cracking in the cold worked 316 material suggests that for this temperature and strain range a fatigue-type failure is dominating and, if present, cavitation is not significantly influencing the deformation process.

Similarly, the creep-fatigue failures of the HT-UPS steel at $600^{\circ} \mathrm{C}$ and $650^{\circ} \mathrm{C}$ with a hold time of 10 minutes were predominately fatigue-driven, based on the predominately transgranular crack propagation. For both the 316 stainless steel and the HT-UPS steel, the addition of the hold time did cause the cracking to initiate in an intergranular manner. This shift in the initiation may explain the slightly shorter lives in creep-fatigue than continuous cycle fatigue. Whether the crack initation becomes intergranular as a result of additional environmental damage due to extended times at temperature or as a result of grain boundary sliding is not clear. Further work includes the analysis of the 30 minute and 60 minute hold time specimens which may provide a condition in which creep-fatigue interaction has occurred.

As mentioned previously, a significant decrease in cycle life was not observed with increasing hold times. For the 316 stainless steel, the addition of a 60 minute hold time at $650^{\circ} \mathrm{C}$ resulted in a decrease in the low cycle fatigue life of less than a factor of 2 . Similar behavior was also observed at $600^{\circ} \mathrm{C}$. This is likely partially due to the high strain range selected for creep-fatigue testing and/or the high strain rate used during testing. Typically, the influence of hold time is less dramatic at higher strain ranges. Additionally, as the failures were primarily fatigue drive, the creep damage and therefore creep resistance of the alloy did not appear to play a significant role in the creep-fatigue behavior at the selected conditions. Additional environmental damage or oxidation on the crack surfaces were observed in the creep-fatigue specimens but the influence on overall life was likely minimal, as substantial reductions in life were not observed with the introduction of a hold time. Increased branching of the cracks at oxidized 
grain boundaries was observed in the longer tests; however, the cracks continued to propagate in a transgranular manner and thus were not likely influenced by the branching.

Interestingly, the relaxed stresses varied as a function of cycle and were directly dependent on peak tensile stresses experienced. The higher the peak tensile stress, the higher the relaxed stress for both the HT-UPS steel and the 316 stainless steel, shown graphically in Figure 11. The stress relaxation period is during which the creep damage accumulates and is quantified as such by the ASME Code procedures. The stress relaxation behavior at this temperature is different than that observed in solid solution nickelbase alloys, such as Alloy 617, at high temperatures (above $850^{\circ} \mathrm{C}$ ). The stresses of Alloy 617 at high temperature are observed to rapidly decrease to a relatively constant stress, regardless of the peak stress.

Future work will include further characterization of the creep-fatigue deformation mechanisms; initially the characterization of the cracking in the 30 minute hold and 60 minute hold HT-UPS and 316 stainless steel specimens. Additional SEM analysis may be performed to determine if cavitation is present at the grain boundaries and further TEM analysis of the dislocation substructures will be conducted. The creep-fatigue characterization of the HT-UPS alloy at a higher temperatures, $700^{\circ} \mathrm{C}$, where the alloy offers exceptional creep strengths will also be conducted. Additionally, creep-fatigue testing of the conventional 316 stainless steel in the annealed condition and the HT-UPS alloy in the heat treated condition will also be conducted. 


\section{REFERENCES}

1. Yamamoto, Y., Brady, M.P., Lu, Z.P., Maziasz, P.J., Liu, C.T., Pint, B.A., More, K.L., Meyer, H.M. and Payzant, E.A. Creep-Resistant, A12O3-Forming Austenitic Stainless Steels. Science 316433436 (2007).

2. Brady, M.P., Yamamoto, Y., Santella, M.L., Maziasz, P.J., Pint, B.A., Liu, C.T., Lu, Z.P. and Bei, H. The Development of Alumina-Forming Austenitic Stainless Steels for High-Temperature Structural Use. Journal of Materials July 12-18 (2008).

3. Maziasz, P. Developing an Austenitic Stainless Steel for Improved Performance in Advanced Fossil Power Facilities. Journal of Materials (July), 14-20 (1989).

4. Taneike, M., Abe, F. and Sawada, K. Creep-Strengthening of Steel at High Temperatures Using Nano-sized Carbonitride Dispersions. Nature 424 294-296 (2003).

5. Yamamoto, Y., Santella, M.L., Brady, M.P., Bei, H. and Maziasz, P.J. Effect of Alloying Additions on Phase Equilibria and Creep Resistance of Alumina-Forming Austenitic Stainless Steels.

Metallurgical and Materials Transactions A 40A 1868-1880 (2009). 